NBER WORKING PAPER SERIES

\title{
PREDATION, TAXATION, INVESTMENT AND VIOLENCE: EVIDENCE FROM THE PHILIPPINES
}

\author{
Eli Berman \\ Joseph Felter \\ Ethan Kapstein \\ Erin Troland \\ Working Paper 19266 \\ http://www.nber.org/papers/w19266 \\ NATIONAL BUREAU OF ECONOMIC RESEARCH \\ 1050 Massachusetts Avenue \\ Cambridge, MA 02138 \\ July 2013
}

We acknowledge the assistance of the Department of Social Welfare and Development (DSWD) and the AFP National Development Support Command (NADESCOM), in the Philippines, of Katherine Levy and Mitchell Downey at UC San Diego, and the comments of seminar participants at the Einaudi Institute of Economic and Finance, the University of Warwick, the Department for International Development (DFID), London, LUISS Guido Carli University, Rome, the International Food Policy Research Institute (IFPRI), Addis Ababa, and those of our colleagues at UCSD, Stanford, and the Empirical Studies of Conflict (ESOC) collaborative. This research was supported by the Office of Naval Research (ONR) through Award N000141110735 at the National Bureau of Economic Research. It builds on research supported by U.S. Department of Defense Minerva research initiative through the Air Force Office of Scientific Research (AFOSR) under Award FA9550-09-1-0314. Any opinions, findings, conclusions or recommendations in this document are those of the authors and do not necessarily reflect views of ONR or AFOSR. All mistakes are ours. The views expressed herein are those of the authors and do not necessarily reflect the views of the National Bureau of Economic Research.

NBER working papers are circulated for discussion and comment purposes. They have not been peerreviewed or been subject to the review by the NBER Board of Directors that accompanies official NBER publications.

(C) 2013 by Eli Berman, Joseph Felter, Ethan Kapstein, and Erin Troland. All rights reserved. Short sections of text, not to exceed two paragraphs, may be quoted without explicit permission provided that full credit, including $\odot$ notice, is given to the source. 
Predation, Taxation, Investment and Violence: Evidence from the Philippines

Eli Berman, Joseph Felter, Ethan Kapstein, and Erin Troland

NBER Working Paper No. 19266

July 2013

JEL No. F52,F54,H22,H25,H41,H56,K42,N47,O1

\begin{abstract}
$\underline{\text { ABSTRACT }}$
This paper explores the relationship between investment and political violence through several possible mechanisms. Investment as a predictor of future violence implies that low private sector investment today provides a robust indicator of high violence tomorrow. "Rent-capture" or predation asserts that investment increases violence by motivating extortion by insurgents. A "hearts and minds" approach links investment to political violence in two possible ways: through an opportunity cost mechanism by which improved economic conditions raise the cost of rebel recruitment; and through a psychological "gratitude" effect which reduces cooperation of noncombatants with rebels. Finally, tax capture implies that government will increase coercive enforcement in an attempt to control areas where increased investment increases tax revenue. We lay out these mechanisms in a framework with strategic interaction between rebels, communities, government and firms within an information-centric or "hearts and minds" counterinsurgency model. We test these mechanisms in the context of the Philippines in the first decade of this century, using information on violent incidents initiated by both rebels and government and new data on industrial building permits, an indicator of economic investment. Increases in investment are positively correlated with both rebel and government initiated violence. In the context of our theory that constitutes unequivocal evidence of predation, is consistent with tax capture, and weighs against predictive investment, opportunity costs or gratitude being a dominant effect.
\end{abstract}

\author{
Eli Berman \\ Department of Economics, 508 \\ University of California, San Diego \\ 9500 Gilman Drive \\ La Jolla, CA 92093 \\ and NBER \\ elib@ucsd.edu \\ Joseph Felter \\ CISAC and Hoover Institution \\ Stanford University \\ Encina Hall, C222 \\ Stanford CA 94305-6165 \\ felter@hoover.stanford.edu
}

\author{
Ethan Kapstein \\ McCain Institute for International Leadership \\ Arizona State University \\ 1777 F St. \\ Washington DC 20006 \\ and NBER \\ ethan.kapstein@asu.edu \\ Erin Troland \\ University of California \\ San Diego Department of Economics \\ 9500 Gilman Drive \#0508 \\ La Jolla, CA 92093-0508 \\ etroland@ucsd.edu
}




\section{Introduction}

In canonical models of economic growth and development, a powerful underlying assumption is that market exchange takes place against a background of peace, or an absence of violent conflict. Such words as "civil war" and "rebellion" generally do not appear in the leading textbooks on economic growth (see, for example, Jones 2002), and one of the best-selling texts on the economics of development devotes just one paragraph to all forms of political instability including inter-state and civil wars, coups d'etat, and rebellions (Perkins et.al. 2013, 76). This marginalization of conflict in the relevant economics literature seems at odds with the actual experience of many if not most developing countries.

The 2011 World Development Report (WDR), for example, counts a billion and a half people living in countries affected by fragility, conflict or violence, and identifies organized violence as an impediment to long-run economic growth. Violent conflict can influence a nation's development through many different channels, including the loss of human and physical capital, the shift in public spending toward the military and away from social goods like education and health care, and the weakening or destruction of political, social, and economic institutions, including property rights. ${ }^{1}$ At the same time, some scholars and policy-makers have argued that economic growth and development can contribute to peace through a variety of different mechanisms. Hanson, Iyengar, and Monten (2011), for example, suggest that job creation programs can suppress insurgencies by raising the opportunity costs of fighting, while counterinsurgency expert David

\footnotetext{
${ }^{1}$ The link between such institutions as property rights and long-run growth has been of particular concern to economists since at least the pioneering work of Douglass North (1981). Svensson (1998), for example, extended North's work by modeling the effects of political instability on property rights and, in turn, on investment rates. Gradstein (2004) argues that the enforcement of property rights and economic growth are self-reinforcing. Building on this and related research, the WDR has emphasized the crucial role of improved governance in securing people and property if growth is to be achieved (WDR 2011, 1).
} 
Kilcullen has recently asserted that it is "development... by civilian agencies" which "will ultimately win the war" (Kilcullen 2010, 32).

While most development agencies do not have an explicit mandate to combat violence, governments often rely on the tools of economic development to support an objective of "winning the hearts and minds" of local populations, as has recently been the case in both Afghanistan and Iraq. ${ }^{2}$ Informing that reliance on economic policies and programs is a belief that development is a generally beneficial process from the standpoint of a government trying to reduce or end political violence. However, economic activity could also invite insurgent rent-seeking and predation (Grossman 1999; Collier 2000).

The question of whether economic development fuels or reduces rebellion is of central importance to both the body of social science theory aimed at understanding the development process and to public policies aimed at shoring up fragile states (Blattman and Miguel 2010; World Development Report 2011; World Bank 2008). In this article we explore the relationship between economic investment and violent civil conflict by developing a unified model and testing its predictions using data from the Philippines, a nation which has suffered from "perpetual wars" since the arrival of the Spaniards in 1565 and continues to face domestic insurgency despite a recently negotiated peace treaty with some rebel groups (Morales 2003). Building on the three-sided strategic model of a counterinsurgency campaign developed by Berman, Shapiro and Felter (2011, henceforth BSF), the model we present here incorporates a variety of additional mechanisms through which economic activity may affect violence. In BSF, civilians choose whether or not to provide intelligence regarding insurgent activity to a government which both provides public goods and

\footnotetext{
${ }^{2}$ For instance, since the end of the Second World War, the United States has assisted allies in major insurgency campaigns in Vietnam, Iraq, and Afghanistan, and less intensive conflicts in Central America, Somalia, and parts of the Middle East. Other countries have also fought these types of wars, including Britain (in Aden, Cyprus, Kenya and Malaya), France (in Algeria and Indochina), and the Philippines (throughout its island chain).
} 
pursues rebels. We add a new strategic actor to the BSF model, firms, which choose a level of investment, that is both taxed by government and extorted by rebels.

In terms of testable implications, earlier research has identified at least three mechanisms which would predict a negative correlation between violence and investment, and two which would predict a positive correlation. The opportunity costs mechanism posits that providing better outside opportunities (i.e. employment) to rebels increases the cost of participation in the insurgency (Hanson, Iyengar, and Monten 2011; Dube and Vargas 2010). The gratitude mechanism suggests that civilians will be grateful to the government for increased economic activity, and thus withdraw support for the insurgency as a reward to the government for its efforts (Kilcullen, 2010). The investment mechanism hypothesizes that the higher the level of investment today, the lower will be violence tomorrow; current investment thus predicts future violence (Kapstein and Converse 2008). These three mechanisms share roughly the same prediction: that increased investment correlates with decreased violence.

Rent capture, or predation, has the opposite prediction: business investment presents extortion opportunities for insurgents. As a result, insurgents may use violence to secure their ability to extort such activity (Grossman 1999; Collier 2000). Analogously, the tax capture mechanism implies that a government which taxes investment will increase its use of coercive force to in order to enable taxation in regions with increased investment (Fearon 2008). Thus, predation and tax capture are two additional mechanisms which predict that changes in investment will be positively correlated with both rebel initiated and government initiated violence. The attention to violence initiated by government forces, both in a broader theory and in the empirics, represents an expansion on our previous research (Berman et al, 2012).

Our omnibus model reveals some subtleties. First, whether rebel violence increases or decreases optimal investment levels depends on its' effects on effective taxation by government and 
predation by rebels. Second, investment might induce either an increase or a decrease in rebel violence, since violence raises the rate at which rebels can extort but may reduce the effective incidence of that predation by antagonizing civilians who deliver territorial control to government rather than rebels.

We apply that expanded model to a new dataset on investment activity in the Philippines, combined with detailed data on violence. Philippine insurgent groups include Communist revolutionaries operating throughout the country, Muslim separatists in the southwestern provinces of Mindanao island seeking independence, and extremist groups with ties to international terrorist organizations who engage in kidnapping for ransom and other illicit activities in the southern Philippine islands of the Sulu Sea (on the Communist insurgency see International Crisis Group 2011; on the Islamic insurgency see International Crisis Group 2008; and for an historical overview see Morales 2003). The Philippines is among the few countries during the period of this study in which economic development programs are integrated into military operations via the Armed Forces of the Philippines' "National Development Support Command" (NADESCOM), whose mission includes the deployment of economic programs to counter insurgent violence and activity.

Data on investment are very difficult to come by at a subnational level in most developing countries. In the Philippines we are fortunate to have found a proxy: detailed information on the value of industrial building permits, which are available at the province level for the entire country, including poorly controlled regions. New construction requires permitting, as does ongoing renovation of existing structures.

To get a sense of these data it's helpful to see the spatial distribution of investment and political violence. The top left panel of Figure 1 displays the population distribution of Philippine provinces (averaged between 2000 and 2007). About a quarter of Filipinos live in the eight provinces surrounding Manila bay, on the west side of the northernmost island of Luzon. The long island of 
Cebu, in the central Philippines (which points northeast) also has high population density, with about $4 \mathrm{~m}$ inhabitants. Provinces in northern Luzon, the eastern shore of the southern island of Mindanao, and the southwest archipelago of Sulu are relatively sparsely populated.

The top right panel illustrates the spatial distribution of investment, as measured by the value of industrial building permits (measured in 1000s of PHP per capita). Investment is generally concentrated in highly populated areas. Investment is especially high around Manila and in Cebu, and is very light in northern Luzon, along the eastern edge of the country, and in eastern Mindanao, including the Sulu Archipelago.

The bottom two panels illustrate casualties per capita caused by rebel initiated events (on the left) and government initiated events (on the right). Two clear patterns emerge. First, rebel and government initiated casualties tend to occur in the same provinces. Second, political violence and investment show a strong negative correlation across space: Investment per capita is high where violence is low, around Manila and in Cebu, while violence is high in low investment (and sparsely populated) provinces of northern Luzon, Samar (on the central east coast), and Mindanao, especially in the Muslim majority provinces of Mindanao which make up the Autonomous Region of Muslim Mindanao: the Sulu Archipelago in the southwest (Basilan, Sulu and Tawi-Tawi) and the two provinces on the west-central coast of Mindanao (Lanao del Sur and Maguindanao). Anecdotally, these high violence, low investment areas tend to have norms favoring rebels, relative to the rest of the country. Informed by the negative spatial correlation between rebel violence and investment, we will build a model in which rebel predation can discourage investment.

Once we apply our analysis to data, the results are consistent with a theory of predation. The empirics are straightforward: though levels of investment and violence are negatively correlated, as the maps illustrate, we will see that changes in investment are positively correlated with changes in violence, both rebel and government-initiated. These findings thus call into question the role of 
investment in reducing violence. Moreover, since the measure of investment is private rather than public, predatory violence is not a symptom of poorly-conceived economic development projects launched by foreign donors or distant governments. The results also provide some empirical support for the idea that new investment motivates the use of coercive force by government (on this point see Besley and Mueller 2012). We discuss the implications of these results for the design of development programs.

The paper proceeds as follows. After a brief literature review we develop an omnibus theory of investment, taxation and political violence which encompasses all the mechanisms mentioned above. Section three describes the data. Section four reports empirical analysis, section five provides discussion and section six concludes.

\section{Investment and Violence: What's the Connection?}

Civil wars and insurgencies are a common feature of modern political life (Blattman and Miguel 2010). Besides their detrimental effects on local governments and populations, these conflicts can also entrap foreign governments for considerable periods of time. Fragile states can harbor terrorists; drive migration and refugee flows; and disrupt trade and investment. They can also spawn gross violations of human rights. For these among other reasons, the international community, including scholars and policy-makers, has taken a heightened interest in how such conflicts are managed. However there is no general consensus on the best way to do so.

Understanding the origins of communal violence has been the aim of considerable academic research. Not surprisingly, economists have emphasized the self-interested nature of such conflicts, with much of the relevant literature conceptualizing such conflict as a contest for available resources (see Hirshleifer 2001; Kapstein 2002). As Jack Hirshleifer puts it in The Dark Side of the Force, "There are two main methods of making a living ... the way of production and exchange versus the way of predation and conflict" (Hirshleifer 2001, 1). 
This insight has generated the widespread view that poverty is a powerful contributor to violence (see Fearon 2008 for a review of the relevant literature and a counter-argument). If the returns to production are low and the gains from rebellion are high, then fighting may be preferable to peaceful resignation. In this context it is worth noting that the Mindanao region of the Philippines, which has been the site of a violent pro-Muslim insurgent movement, is also the poorest region of that country, with levels of per capita income that are half the national average (see Government of the Philippines, National Statistics Coordination Board, n.d.). It is also notable that rebel predation has been commonplace in that region. Morales (2003), for example, notes that Mindanao rebels engaged in widespread extortion along the highways.

In a related vein, Miguel, Satyanath, and Sergenti (2004) launched an influential literature that uses variation in rainfall as an instrument for analyzing the effects of changes to (agricultural) incomes on outbreaks of violence (for a literature review see Sarsons 2011). They posit that droughts lead to lower crop production and thus lower incomes, leading to greater levels of rioting, conflict, and even civil war. This research has been extended to examine the effects of rainfall on democratic stability in Africa (Bruckner and Ciccone 2011) and political stability in Egypt (Chaney 2010). Sarsons (2011), however, finds for the case of India that even in regions which are protected from rainfall fluctuations by dams, rioting still occurs in the presence of droughts, suggesting that the channel may not in fact be through incomes, or at least not through incomes alone.

If conflicts over scarce resources are at the root of at least some civil wars and insurgencies, it would seem to follow that economic development could serve the cause of peace. Indeed, a commonly held view in both the academic and policy literatures on insurgency is that economic development (broadly defined here to include economic activity by both the public and private sectors) can help promote a "stable" political environment in which government authority is generally recognized and respected. In the context of Afghanistan, for example, a U.S. Army War 
College study argues that "development is a means of turning Afghans away from the insurgency and thereby creating a stable environment in which the Afghan government can exert its authority" (Malkasian and Meyerle 2009, 6). Similarly, a report to the U.S. Senate Committee on Foreign Relations states that "foreign assistance can be a vital tool for promoting stability in Afghanistan" (U.S. Senate, 2011, 1). This type of assertion has been made by policy-makers with reference to every postwar conflict involving insurgent violence, from the Malayan uprising of the 1950 s to the Iraq and Afghan wars (Marston and Malkasian 2008). The concept of "winning hearts and minds" (WHAM) has featured prominently in many counterinsurgency campaigns since it originated with British General Sir Gerald Templer in the Malaya campaign of 1948-1960 (Stubbs 2008).Yet these sources are typically vague about the mechanism by which economic activity reduces insurgent violence.

The academic literature attempts to be more specific, developing several distinct channels which relate economic activity to insurgent violence. First, a primary objective of the counterinsurgents, in some cases, may be to encourage the civilian population to divulge useful information and intelligence about the insurgency. To achieve this objective, counterinsurgents may use economic instruments targeted at a tactical level to motivate or reward such behavior. This strategy might be termed "information-centric counterinsurgency," as developed formally by BSF.

Closely related are two other "hearts and minds" theories of counterinsurgency. One is that the civilian population can be "won over" to the government's side by the general provision of public goods and the promise of future economic growth, and that in gratitude they stop providing recruits and resources to insurgents. Another is the aforementioned "opportunity cost" approach to insurgency, suggesting that the greater the economic growth and the better the job prospects, the more costly it becomes to engage in the insurgency. 
Fourth, far from impeding violence, some scholars argue that economic activity encourages insurgent violence by inducing insurgents to engage in rent-seeking behavior or predation (Hirshleifer, 1989; Collier and Hoeffler 2004). ${ }^{3}$

Yet careful empirical research provides arguments both for and against that particular causal relationship. Hanson, Iyengar, and Monten (2011), for example, find that increased spending on labor-intensive development programs is associated with decreases in violence, while Berman, Shapiro, Felter and Callen (2011) find the opposite relationship between unemployment levels and insurgent attacks, in Afghanistan, Iraq and the Philippines. In short, the relevant theoretical and empirical studies have not yet forged a consensus on the economics-insurgency connection.

In this paper we develop and test hypotheses regarding that connection, building on several strands of the economics literature. The first strand, which we label "predictive investment," draws on research on financial markets, and particularly the efficient market hypothesis (Fama 1970). It posits that domestic investors process all relevant information about the economy's future trajectory (including policy information) before making their allocation decisions, and that increasing levels of investment in country $\mathrm{x}$ and time $\mathrm{t}$ reflect, all things being equal, relative optimism about the country's economic future.

Kapstein and Converse (2008), for example, find that domestic investment in newly established democracies is lower in those democracies that are overturned within their first five years of existence than in those which endure for the longer-run; in other words, domestic investors appear to have some knowledge about the future degree of political instability. Fielding (2003) examines investment levels in Israel and Palestine over time and finds that investment in construction and capital goods falls during those periods of the greatest "intifada" (or Palestinian

\footnotetext{
${ }^{3}$ Following Fearon (2004), predation in the face of renewed economic activity could reflect the insurgents' skepticism about the government's commitment to a peaceful solution. As Fearon notes, once the balance-ofpower reverts to the government side it could renege on the agreement it had reached during the struggle.
} 
uprising) violence. He further argues that a credible commitment to peace would significantly increase investment levels in those sectors. Looking at the case of Iraq, Chaney (2007) examines the price of sovereign bonds and finds that prices reflect the views of investors about the country's future political stability. Similarly, Coyne et.al. (n.d.) test the relationship between equity market prices and violence in Sri Lanka, and they find that the stock market provides a robust predictor of future peace and violence in that country. In a recent paper, Besley and Mueller (2012) link housing prices to the frequency of killings in Northern Ireland. They find that once British forces brought some stability to Northern Ireland, housing prices began to increase. These price increases continued as British forces maintained a presence in the region, thus making a credible commitment to investors. This interaction between military forces and investors promoted a reduction in violence, which further drove prices upward. In short, all these studies share the view that investment decisions made today generally provide an accurate reflection of political stability in the future. In the context of the present study, predictive investment suggests the following hypothesis:

H1: Increased investment will be associated with decreased insurgent violence.

Two other mechanisms, namely the "opportunity cost" (Dube and Vargas 2010) and "gratitude" ${ }^{4}$ theories, share the opposite prediction, that increased economic activity will reduce rebel violence.

\footnotetext{
${ }^{4}$ Kilcullen (2010) explains from a skeptical perspective: "There is also a belief, unfounded in reality, that development assistance generates gratitude, or "hope," in the population and thereby of itself encourages them to support the government. Field experience in both Afghanistan and Iraq, however, has shown that insurgent intimidation easily overcomes any residual gratitude effect, while historical studies have shown that in civil wars and insurgencies, popular support tends to accrue to locally powerful actors rather than to those actors the population sees as more congenial..." (p. 67). In what follows, gratitude and opportunity cost mechanisms will have similar testable implications.
} 
A fourth theory we examine, predation, is the polar opposite to the investment theory. It builds on the work of Grossman (1999), Collier (2000), and Hirshleifer (2001). Simply stated, predation theory asserts that in an environment with weak property rights, rebels may increase the use of violence in order to extort resources. Collier argued that efforts at predation would be strongest in societies where wealth was the most concentrated, especially in the form of natural resources, though the same argument could apply to , the rebels in Mindanao, who taxed highway traffic, and to the Communist insurgents in the Philippines who imposed "revolutionary taxes" on agriculture (Morales 2003).

Building on this work, along with the more recent research of Collier and Hoeffler (2004), Sambanis (2003), and Ross (2004), Crost, Felter and Johnston (2012) argue in the case of the Philippines that "if insurgents expect that [economic] development projects will weaken their position, they have an incentive to prevent their successful implementation, which may exacerbate conflict." Observing economic activity in their midst, the insurgents will seek to disrupt it before the government can earn the associated political rents. Alternatively, insurgents may "shake down" the investment projects as a way of gaining income. In either case, more violent episodes may be expected to occur alongside economic development programs.

As Crost, Felter and Johnston (2012) note, there seems to be substantial anecdotal support for this theory, in the form of frequent attacks on both aid workers and infrastructure projects. In 2010 alone, for example, over 100 relief workers were killed in Afghanistan (Nordland, New York Times, December 13, 2010). Further, major infrastructure projects have been targeted by insurgents, who have also successfully targeted the government and foreign assistance community for protection money as the price of allowing those projects to move forward (Rubin and Risen, New York Times, May 1, 2011). In essence, these projects have been "taxed" by the Taliban. Stating this "predation" theory as a testable hypothesis: 
H2: Increased investment will be associated with increased insurgent violence.

It would be tempting to take these hypotheses to the data in order to distinguish between theories, as the literature generally has done. Yet an omnibus model that accommodates all of those mechanisms requires extra assumptions in order to generate both $\mathrm{H} 1$ and $\mathrm{H} 2$. The class of theories (and indeed military doctrines) that incorporate the behavior of noncombatants, including opportunity costs and gratitude, are often called "winning hearts and minds." The recent literature has emphasized approaching them as a three-sided game, in which insurgents, counterinsurgents, and communities of noncombatants all act strategically (U.S. Army 2007; BSF). That class also includes information-centric counterinsurgency, which predicts that only particular types of targeted economic activity (i.e. small-scale, local development projects) will be violence reducing. These small-scale programs, however, have high requirements for detailed local knowledge about the population and its grievances, which may be difficult to acquire in conflict zones.

In order to accommodate all of these possible mechanisms from the literature we expand the three-sided game of BSF in several ways, introducing firms and investment in order to allow predictive investment, allowing extortion by rebels in order to incorporate predatory violence, and including taxation by government. Once more fully theorized, we find that some of the intuitive predictions flowing from simpler models are potentially overturned. For instance, firms anticipating increased rebel violence may invest less, as they expect to be extorted at a higher rate. On the other hand, firms may choose to invest more, as rebel violence increases the probability that antagonized noncombatants will enable government control (by sharing tactically relevant information), reducing the effective rebel extortion rate to zero, and contradicting H1. Moreover we will see that H2 only follows from predation theory under particular assumptions. 
Fortunately, in distinguishing between hypotheses we have the further benefit of being able to observe government use of violence, which we call enforcement. We will expand our omnibus model to include the mutual response of enforcement and investment as well. The next section lays out all of those causal mechanisms, allowing us to interpret the Philippine data in a broadly theorized context.

\section{Theoretical Framework: Investment, Predation, Taxation, Opportunity}

\section{Costs, and Gratitude}

To understand how investment might be related to insurgent violence we first examine the motivations and constraints of insurgents, counterinsurgents, communities of noncombatants, and firms. In this section we expand the information-centric model of BSF to explicitly include four additional mechanisms by which investment could affect violence: opportunity costs, gratitude, predation by rebels, and tax capture by government. To preserve symmetry and realism we balance predation by insurgents with taxation of firms by government, allowing us to discuss the effects of both. Violence by rebels and enforcement activity by government -both observable in the Philippine data, will be equilibrium outcomes of a four-way strategic interaction between rebels, community, government and firms, building on a model of street gangs proposed by Akerlof and Yellen (1994). That framework is illustrated schematically in Figure 2. We start with an informal description and state a minimal model, referring the reader to the Appendix for proofs.

Consider an environment in which insurgents ambush police and military patrols, or set improvised explosive devices (IED) to attack them. These insurgents finance their operations by extorting local businesses with threats of violence, their attacks on government forces making these threats credible and undermining the ability of government to protect extortion targets. Preparations for insurgent attacks are likely to be observed by noncombatant community members who could 
report the insurgents to government forces. Those reports enable government forces to use their superior technology and equipment to disrupt insurgent activity, improving government's chances of controlling the territory.

In that dangerous environment decisions must be made about five types of actions, each of which is consequential for all participants. Community members decide whether to share what they know with authorities, possibly delivering control to government if they do. That decision is influenced by how violence, consumption and service provision by government will affect their welfare, as well as by persistent predispositions to favor one side over another, which we model as norms of cooperation with rebels. Rebels choose levels of violence, balancing their benefits to violence in extracting concessions from government and in extorting rents from firms against the chances that violence antagonizes community members and dissuades investment. Government decides how much effort to expend in attacking rebels and in providing services to the community, mindful of the costs of these activities, the cost of violence, and the tax revenue accrued when territory is controlled. Firms choose investment levels, anticipating taxation and possible predation.

$$
\text { [Insert Figure } 2 \text { about here.] }
$$

More formally, that environment can be modeled as follows.

\section{A. Assumptions}

1. Players and Actions

The government, G, seeks to reduce violence through counterinsurgency effort and service provision, at minimal cost. A rebel group, R, seeks to impose costs on government by attacking it, ${ }^{5}$ and to extort rents. A utility maximizing community, C, can help deliver control of territory to

\footnotetext{
${ }^{5}$ Attacks that target civilians are considered in BSF, Appendix A. Violence has to occur in equilibrium, rather than just the threat of it, since we observe violence in the data. Violence is inefficient in a Coasian sense; for it to occur there must be incomplete contracting ability between rebels and government (Fearon 2004; Powell 2006). This is not a very restrictive assumption; governments and rebels often have trouble credibly committing to bargains.
} 
government by anonymously sharing information about rebels. Firms, F, choose levels of investment to maximize profits.

\section{Sequence of Play}

Information sharing by the community requires no preparation, while service provision, counterinsurgency efforts and rebel violence are less flexible, requiring pre-deployment of people and resources, so we assume that $\mathrm{C}$ can move last. Play proceeds in four stages:

(\#1) Nature draws community norms favoring rebel (over government) control of their territory, $n$, from a uniform distribution $\mathrm{U}\left[n_{L}, n_{U}\right] ; n$ is private to $C$. To capture predation, we assume that rebels extort investments at a rate $0<\theta_{\mathrm{R}}<1$, while government taxes at a rate $0<\theta_{\mathrm{G}}<1{ }^{6}$

(\#2) G chooses a level of public goods to provide, g, and a level of enforcement (counterinsurgency) effort, $m$. R simultaneously chooses a level of violence, $v$, to attempt against $G$. F chooses a level of investment, $I$.

(\#3) C decides how much information, $i$, to share with $G$, having observed the actions of $G$ and $R$. (\#4) Uncertainty regarding control of territory, $a$, is resolved, and payoffs occur, as explained below.

\section{Technology of control}

Control of territory is represented by a binary variable, $a$, which is equal to one if the government controls the territory, and zero if it is controlled by rebels. The probability of government control is

$$
\mathrm{P}(a=1)=\mathrm{h}(m) i
$$

where $m$ is enforcement (counterinsurgency) effort by $\mathrm{G},(m \geq 0), \mathrm{h}(m): \mathrm{R}^{+} \rightarrow[0,1]$ is a monotonically increasing, concave contest success function, with $\mathrm{h}(0)=0$ and $\mathrm{h} \rightarrow 1$ as $m \rightarrow \infty$.

\footnotetext{
${ }^{6}$ Assume that $n_{\mathrm{L}}$ and $n_{U}$ span enough of the real line to allow $n_{\mathrm{L}} \leq v+g+\left(\theta_{\mathrm{R}}-\theta_{\mathrm{G}}\right) I \leq n_{\mathrm{U}}$. That will be equivalent to assuming that the support of $n$ is broad enough to allow neither side to fully determine information sharing through its actions.
} 
Here $i$ is the level of information that $C$ chooses to share with $G,(1 \geq i \geq 0)$. (All variables are real numbers unless otherwise specified.) Consistent with current doctrine, this makes some minimal information sharing a necessary condition for government control (U.S. Army, 2007, 1-23). Rebel control does not altogether exclude government forces. It implies that attempted rebel violence against those forces will cause them damage. In contrast, attempted rebel violence in government controlled areas fails to do harm. ${ }^{7}$

\section{Payoffs}

Community: The community has a representative member whose utility is affected by who controls territory.

Utility is given by

$$
\mathrm{U}_{\mathrm{C}}(a, g, n, v)=\mathrm{u}[c+g-n] a+\mathrm{u}[c-v](1-a) .
$$

If $a=1$ (government control) then the community consumes $c \geq 0$ and benefits from government services, $g \geq 0$, so it attains utility $\mathrm{U}_{\mathrm{C}}=\mathrm{u}[c+g-n]$, where $\mathrm{u}[$.$] is continuously differentiable and$ monotonically increasing. Services are local public goods such as safety, justice, education, health, welfare, garbage collection, utilities, or infrastructure. Community norms favoring rebel control, $n$, generate disutility when the government is in control.

Alternatively, if $a=0$, rebels may successfully carry out violence, $v \geq 0$, against government targets. Under rebel control, community members will attain utility $\mathrm{U}_{\mathrm{C}}=\mathrm{u}[c-v]$. Rebel violence, $v$, is not directed against community members per se, but they suffer from it nonetheless, either

\footnotetext{
${ }^{7}$ That stark assumption is relaxed in BSF, Appendix A.
} 
because they are accidentally affected by crossfire (so-called "collateral damage"), or because they empathize with government employees or value government targets. ${ }^{8}$

Under rebel control the community does not benefit at all from government services, $g$, either because the government withdraws services when it cannot protect its employees and contractors, or because it conditions local public good provision on control, as collective punishment. 9

This is a "rational actor" model, in the tradition of Popkin's (1979) description of Vietnamese peasants; noncombatants make choices based on a rational calculation of self-interest, rather than an overwhelming ideological commitment to one side or another. Ideological commitments are captured by the term $n$, but on the margin the behavior of government and rebels can also influence noncombatants' decisions.

Incorporating the uncertainty that $C$ faces about $a$, C's payoff is the expected utility function

$$
\left.\mathrm{EU}_{\mathrm{C}}(g, v, n, m)\right|_{\mathrm{n}}=\mathrm{u}[c+g-n] \mathrm{h}(m) i+\mathrm{u}[c-v](1-\mathrm{h}(m) i) .
$$

Rebels: Rebels use violence to impose costs on government, either in an attempt to extract concessions, or in an effort to overthrow the government altogether (Tilly, 1978). These attacks would typically involve targeting a patrol with an IED, ambushing a patrol with direct fire, or attacking a checkpoint. Let G's cost of rebel violence be $\mathrm{A}(v)(1-a)$, which accounts for the damage

8 BSF generalize to allow rebel violence to affect the community when $a=1$, in two ways (in an appendix): they introduce violence directed at the community; and allow the community to suffer disutility from government suppression of that violence.

${ }_{9}^{9}$ Conditionality might be unusual for a social welfare maximizing government, an NGO or interntional organization such as the World Bank (Crost, Felter, and Johnston 2012), but would be standard practice for a government concerned about insurgents. Conditionality of development programs is implied by the COIN field manual in the discussion of economic development: "Ensure that noncompliance with government policies has an economic price. Likewise, show that compliance with those policies is profitable. In the broadest sense, counterinsurgency operations should reflect that 'peace pays'." (U.S. Army 2007, 5-49, p.173). Survey evidence reveals that a majority of CERP implementers in Afghanistan practice conditionality (BSF, note \#15). 
caused by an attack. R's benefit from violence is then $\mathrm{U}_{\mathrm{R}}=\mathrm{A}(v)(1-a)$. We assume that $\mathrm{A}(0)=0$ and that $\mathrm{A}$ is an increasing, concave function. $\mathrm{R}$ also gains extortion income from firms' investment, $\theta_{\mathrm{R}}(\nu) I$, where the extortion rate $\theta_{\mathrm{R}}$ is an increasing, concave function of rebel violence, $v$. Rebels' cost of violence is $\mathrm{B}(v, I)$, which is increasing and convex in $v$.

We integrate the possibility of an opportunity cost mechanism of violence into the model by including investment, $I$, in rebels' cost of violence, $\mathrm{B}(v, I)$. Assuming that investments are in capital which complements labor, those investments increase wages, which in turn raise the marginal cost of violence as rebels must pay more for recruits with an increased value of time, i.e., a positive crosspartial, $\frac{\partial^{2} B}{\partial v \partial I}>0 .{ }^{10}$ Gratitude, the idea that $\mathrm{C}$ will resist recruitment by rebels if the government behaves in a way that encourages investment, would have the same prediction of a positive crosspartial, $\frac{\partial^{2} B}{\partial v \partial I}>0 .{ }^{11}$ We discuss the implications for data below.

Rebels then face an expected payoff function,

$$
\begin{gathered}
\mathrm{EU}_{\mathrm{R}}(m, g, v, a, I)=\mathrm{E}\left[\mathrm{A}(v)(1-a)+\theta_{\mathrm{R}}(v) I(1-a)-\mathrm{B}(v, I)\right]=\left[\mathrm{A}(v)+\theta_{\mathrm{R}}(v) y\right](1-p)-\mathrm{B}(v, I), \\
\text { where } p \equiv \mathrm{h}(m) \mathrm{E}(\imath)
\end{gathered}
$$

Note that $p=\mathrm{P}(a=1)$ for rebels, for whom $i$ is a random variable.

Government: The government bears the costs of violence as well as the costs of enforcement, $m$, and of service provision, $g$, while collecting revenue $\theta_{\mathrm{G}} I$ if it achieves control. It has expected net costs

$$
\begin{gathered}
\mathrm{EC}_{\mathrm{G}}(v, m, g, a, I)=\mathrm{E}\left[\mathrm{A}(v)(1-a)+\mathrm{D}(m)+\mathrm{H}(g)-\theta_{\mathrm{G}} I a\right] \\
=\mathrm{A}(v)(1-p)+\mathrm{D}(m)+\mathrm{H}(g)-\theta_{\mathrm{G}} I p
\end{gathered}
$$

\footnotetext{
${ }^{10}$ We will assume that all functions are twice continuously differentiable in all terms from here on in.

${ }^{11}$ Gratitude could alternatively be modeled more narrowly, such as reciprocation for provision of a specific service by government. In that sense this test has low inferential power.
} 
This government is not a social welfare maximizer. This is not necessarily a normative criticism. We remove welfare considerations from the government's objectives in order to focus on the optimal behavior of a government whose first priority is repressing violence. This assumption may fit a government more concerned about externalities of violence than it is about the welfare of residents - especially non co-ethnics or those in the periphery, or it may describe a dictatorship or dysfunctional democracy.

We assume that $\mathrm{D}(0)=\mathrm{H}(0)=0$. We further assume that the cost functions $\mathrm{D}($.$) and \mathrm{H}($. are monotonically increasing. Convexity is a reasonable assumption for $\mathrm{D}($.$) and \mathrm{H}($.$) , for a$ government facing increasing marginal costs in revenue generation on the one hand and diminishing returns in service provision and counterinsurgency technologies, on the other. We also assume that there are no fixed costs to enforcement so that $\mathrm{D}^{\prime}(0)=0 .{ }^{12}$

Firms: A novel feature of the Philippine data is the availability of building permits, which measure private sector investment, inviting an extension of existing models of insurgency to include investment by private firms. These investments may be taxed by government or extorted by rebel predation, both of whom take account of the effects of their choices on revenue.

Firms' profit is $x(I)-\left(1+\theta_{G}\right) I$ under government control, and $x(I)-\left(1+\theta_{R}\right) I$ under rebel control. Successful violence increases the rate at which rebels predate, $\theta_{\mathrm{R}}(v)$, which is an increasing and concave function. For instance, $\theta_{R}=1$ would be equivalent to full rebel expropriation of investment. Government revenue is $\theta_{G} I$ if $\mathrm{a}=1$; rebel revenue is $\theta_{R} I$ if a $=0$.

Firms face expected profits

\footnotetext{
12 A weaker assumption $\mathrm{A}\left(n_{U}\right)>\mathrm{D}^{\prime}(0)$ is sufficient to imply a unique equilibrium in proposition \#2 below. It implies that the fixed costs of $m$ are not so high that communities maximally predisposed to not share information are never cost effective to not engage at all. See BSF for proof.
} 
(4) $\mathrm{E} \Pi(v, m, g, a, I)=\chi(I)-I-\left[\theta_{G} p+\theta_{R}(1-p)\right] I$,

where $x(I)$ is increasing and concave in $I$, with $\mathrm{x}^{\prime}(0)>1+\max \left(\theta_{G}, \theta_{R}\right)$, so that the first unit of investment is profitable. Firms invest to maximize expected profits, anticipating either taxation or rebel predation, our formalization of the predictive investment mechanism.

\section{Equilibrium}

We turn now to analytical results revealing how actors play, solving for subgame perfect Nash equilibrium in pure strategies, starting with the community (step \#3), and proceeding by backwards induction to government, rebels and firms (step \#2). The impatient reader might consider skipping to the discussion of Table 1 in Section B. below, which summarizes optimal responses.

Proposition \#1: The community will share information with government if and only if the value of services provided and the costs of violence exceed norms of noncooperation, when $G$ expends positive effort on enforcement.

Proof: See Appendix.

\section{[Insert Figure 3 about here.]}

Figure 3 illustrates this logic, graphing the expected utility of community members against information revelation, $i$, on the horizontal axis ( when $m>0$ ). The expected utility of the representative community member is a linear function of $i$. The upper line illustrates the case in which that slope is positive, while the lower line shows the case where the slope is negative. C's best response, $i^{*}$, is to fully share information when $\mathrm{U}_{\mathrm{C}}$ is increasing in $i$, (the positive slope in the Figure) and not to share any information otherwise. A slope of zero defines the noncooperation ("no snitching") constraint, the conditions under which the community is indifferent between sharing information with the government or staying quiet. High levels of government service provision, 
violence, and low norms favoring noncooperation all reduce that incentive. Note that regardless of its attitude towards the welfare of the community, G has good reason to provide services in order to influence information flow and thus reduce violence, even though the community is not enfranchised.

Proposition \#2: A unique Nash equilibrium in pure strategies exists for this game. Proof: See Appendix.

Now that we have unique equilibrium solutions for optimal choices of violence, enforcement, investment, services and information sharing, we can examine how variables respond to each other, with an eye to observed patterns in the Philippines.

\section{B. Analytical results on the spatial correlation of investment and political violence}

We begin by considering the spatial patterns observed in the maps of Figure 1, which illustrated the negative spatial correlation of investment and political violence. That correlation is quite persistent, so a reasonable first step is to examine how violence and investment respond to persistent predisposition of communities to favor rebels over government -which would capture norms, longstanding grievances, ethnic differences, religious attitudes, a history of disenfranchisement and other persistent factors, which we label as norms, $n$.

How would differences in norms across regions affect political violence? Since we model norms as a random variable drawn from a uniform distribution, what we define as differences in norms across regions is that the endpoints of that distribution are shifted equally and in the same direction (i.e., $\Delta n_{L}=\Delta n_{U}$ ). Those endpoints are common knowledge (even if the realization, $n$, in stage \#4 is a random variable). 
Proposition \#3: In regions where norms favor rebels, communities have a lower probability of sharing information with government, rebels choose to use more violence, government chooses to provide less enforcement, and government provision of services is the same, all ceteris paribus. Proof: See Appendix.

The intuition for information sharing is illustrated in Figure 3. Increased norms of noncooperation with government imply a greater chance of disutility from information sharing $(n>g+v)$. Rebels, in turn, face a higher probability of controlling territory, which increases their return to violence -both in damage inflicted on government and in predatory rents. Since information sharing complements enforcement, government chooses to enforce less when information flow is expected to be lower. Finally, both the marginal costs and marginal benefits of government from service provision are unaffected by information sharing, so that government service provision is not affected. Recall that these are ceteris paribus results, in which the governments' response to violence and investment are not considered, a point we return to below. As an aid to keeping track of these results, analytical results are summarized in Table 1, except for those on government service provision (as they have no testable implications for observeables).

Key to our analysis is how investors respond to norms, which will depend on their expected returns to investment under government and under rebel control. As we saw in the last proposition, norms that favor rebels reduce the probability of information sharing and with it the probability of government control. If government taxes at a lower (higher) rate than rebels extort, norms favoring rebels decrease (increase) expected returns on investment for firms, and reduce (increase) investment. 
Proposition \#4: Investment is higher (lower) where norms favor government if and only if the government tax rate is less than (exceeds) the rebel extortion rate, ceteris paribus. Proof: See Appendix.

Those two results (propositions \#3 and \#4) provide a way of understanding the observed spatial pattern of investment and rebel violence, suggesting that tax rates are generally lower than extortion rates (even in low violence areas such as the large population centers), so that norms favoring rebels predict both low investment and high rebel violence. Spatial variation in those norms maps out a negative correlation of investment and rebel violence. We should emphasize that norms here proxy for any persistent spatial characteristic that favors rebels over government, including attitudes and grievances, but also topography that lends itself to easy rebellion, difficult enforcement, difficult service provision or low investment.

Proposition \#5: Government enforcement and service provision both increase in rebel violence, ceteris paribus.

Proof: See Appendix.

The logic of the proof is that violence increases damage costs $A(v)$ for government, which increases returns to suppressing the probability of rebel control. Enforcement, $m$, complements both $v$ and $g$ in increasing $p$, so that the optimal response of government to increased violence is to increase both enforcement and service provision. The proposition provides a possible explanation for why the maps in Figure 1 report high enforcement (i.e., high casualties in government initiated political violence) in areas where norms might favor rebels (such as the Muslim majority provinces): though the low probability of information sharing reduces the return to enforcement (through the 
complementarity in the technology of control -Proposition \#3), that effect might be counteracted by the reduction of high levels of rebel violence typical of regions with norms favoring rebels (Proposition \#3).

Proposition \#6: Rebel violence will decline in both government enforcement, $m$, and in government service provision, $g$, ceteris paribus.

Proof: See Appendix.

Note the contrast between the effects of government services and of investment. Government services unambiguously reduce violence because they cannot be extorted by rebels (proposition \#6), whereas investment may increase violence because it can.

Intuitively, $m$ increases the probability of government control, $p$, reducing expected marginal benefits of violence, in terms of both damage and extortion revenue. Government services play a similar role: by increasing the probability that $C$ will share information with $G$, they lower the probability of rebel control, and with it the expected marginal benefit to rebels of violence.

\section{Investment, Taxation and Predation}

The novel aspect of this model is the introduction of firms and investment. To understand the implications of investment we examine the responses of government, firms, and rebels, beginning with government.

How would government respond to an exogenous increase in investment, perhaps in response to a new economic opportunity? The answer is straightforward: increased tax revenue provides an added incentive for government to control territory when investment increases, so that both enforcement, $m$, and services, $g$, rise in response to increases in $I$, as government uses these tools to raise their probability of achieving control. This response by government is the analogue to 
the predatory response of rebels, which has received much more attention in the literature on economic activity and political violence (Grossman 1999; Collier 2000). The next proposition captures that logic.

Proposition \#7: Government enforcement and services both increase in response to investment, holding violence constant.

Proof: See Appendix.

Note that violence must be held constant in this proposition because the response of investment to violence must be accounted for in general equilibrium, which we return to in the discussion below.

How would firms' investments react to increased effort by government to control the territory (through increased enforcement and service provision)? The answer depends on the relative taxation and extortion rates, as we saw above in the discussion of investment and norms. If government taxes at a lower (higher) rate than rebels extort, then increased efforts by government represent increased (decreased) expected returns on investment for firms, and investment will increase (decrease) as firms practice predation (taxation) avoidance.

Proposition \#8: Investment increases (decreases) with both enforcement and service provision, if and only if the government tax rate is less than (exceeds) the rebel extortion rate, holding violence constant.

Proof: See appendix. 
The best response functions of firms when choosing investment and of government when choosing enforcement are illustrated in Figure 4, which illustrates equilibrium in this system in the dimensions of enforcement and investment. The intersection of the government's upward sloping enforcement curve as a function of investment, and the firms' investment curve as a function of enforcement provides an equilibrium solution. The figure illustrates the case in which investment increases in enforcement, which occurs when the extortion rate exceeds the tax rate, the case that we inferred from the discussion of the spatial distribution of investment and violence in Figure 1 and Proposition \#3. Anticipating taking this model to data, that case would predict a positive correlation of investment and enforcement, whether the dominant source of variation is either exogenous shifters of investment or exogenous shifters of enforcement.

[Insert Figure 4 about here.]

The response of investment to rebel violence reflects a second ambiguity, which is not as easily resolved with data. Violence dissuades investment by raising the extortion rate, which we term the "rate effect." This is the basis of the Kapstein-Converse predictive investment mechanism, by which expected violence depresses investment, so that increased investment is a leading indicator of reduced violence -should investors be good predictors of peace. Yet violence may also encourage investment if it reduces the expected incidence of predation (by inducing the community to share information -raising the probability that extortion will be replaced by taxation), and the extortion rate exceeds the tax rate -as we have reason to believe. The rate effect will always dissuade investment, while the incidence effect will induce investment when firms prefer taxation to predation, as indicated by the spatial pattern in Figure 1. 
Proposition \#9: Investment declines (increases) in rebel violence if and only if the rate effect, $\theta_{\mathrm{R}}{ }^{\prime}(v)(1$ $\left.p^{*}\right)$, exceeds (is less than) the incidence effect, $\left(\theta_{\mathrm{R}^{-}} \theta_{\mathrm{G}}\right) f \mathrm{~h}(m)$, holding enforcement and service provision constant.

Proof: See Appendix.

Note that investment declines unambiguously in violence if tax rates are greater than extortion rates, $\theta_{G}>\theta_{R}$, as the rate effect and the incidence effect both decrease investment. Yet the spatial distribution of investment and violence (Figure 1) make that case unlikely.

We are now prepared to take on the central question of how rebel violence reacts to investment. Rebel response to investment is subtle, since rebels, like investors, face countervailing pressures from rate effects on the one hand, and from incidence effects, opportunity costs and gratitude on the other. Increased violence raises the extortion rate. That is the rate (or 'rent-capture') effect emphasized by Collier and Hoeffler (2004). Yet violence also reduces the probability of rebel control of territory, as it antagonizes communities, lowering the expected incidence of any extortion revenue at all. That expected incidence effect is unambiguously violence-reducing. Moreover, our model also allows investment to raise the marginal cost of violence through increased opportunity costs (Hanson, Iyengar, and Monten 2011; Dube and Vargas 2010) and through gratitude (Kilcullen 2010). An exogenous increase in investment amplifies all of these effects, so that the net effect on rebel violence is ambiguous.

Proposition \#10: Violence increases (declines) in investment if and only if the rate effect, $\theta_{\mathrm{R}}{ }^{\prime}\left(v^{*}\right)\left(1-p^{*}\right)$, exceeds (is less than) the sum of the incidence effect, $\theta_{\mathrm{R}}\left(v^{*}\right) f \mathrm{~h}(m)$, and the combined opportunity cost and gratitude effects $\frac{\partial^{2} B}{\partial v \partial I}$, holding enforcement and service provision constant. Proof : See Appendix. 
Given the unclear theoretical predictions about investment and rebel violence in the last two propositions, the following result will help simplify our empirical analysis. If Collier and Hoeffler (2004) are right about rent-capture (the rate effect) dominating the incidence and other effects so that violence increases in investment, then Kapstein and Converse (2008) must be right about predictive investment (i.e., the rate effect) dominating the incidence effect as well.

Proposition \#11: If violence is increasing in investment, then investment must be decreasing in violence, holding service provision and enforcement constant.

Proof: See Appendix.

The intuition for this proposition is this. Rebels increase violence in response to investment only if their expected increase in revenue from the higher extortion rate that violence allows (the rate effect) exceeds their expected revenue decline due to violence cause them to lose control of the territory (the incidence effect). Say that the expected rate effect is worth 100 PHP in extortion revenue to rebels, while the expected incidence effect is $60 \mathrm{PHP}$ in lost extortion revenue. How would firms respond to that increase in violence? They face the same 100 PHP in expected rate effect --increased extortion payments for them. Yet the benefit to firms from the decline in rebel extortion incidence (60 PHP) is counteracted by some increase in government taxation incidence, making the net expected benefit to firms less than 60 PHP. If the rate effect dominates the incidence effect for rebels (an expected net revenue increase of $40 \mathrm{PHP}$ ), causing an increase in rebel violence, then it must dominate the incidence effect for firms (a net expected cost increase of at least 40 PHP, including extortion and taxation) causing a decline in investment. 
The slopes of best response functions derived in propositions \#3 through \#10 are summarized in Table 1, with question marks denoting the two ambiguously signed slopes. Proposition \#11 implies that if $\mathrm{dv}^{*} / \mathrm{dI}>0$ (fourth column, second row) then $\mathrm{dI} * / \mathrm{dv}<0$ (second column, fourth row).

\section{Comparative statics in investment and violence}

A useful touchstone for empirical analysis of rebel violence and investment is the case in which rebel predation is entirely absent, $\theta_{\mathrm{R}} \equiv 0$. That case is illustrated in Figure \#5. Firms have a downward sloping $I^{*}$ curve in violence, since the rate effect of predation is absent, and the incidence effect on firms is unambiguously negative (since violence raises the probability of government control, which increases the probability of taxation, dissuading investment). ${ }^{13}$ (The indirect effects of violence on investment would also be negative, since violence induces an increase in both enforcement and service provision, which further reduce investment.). In the absence of predation, rebels have no direct incentive to increase violence in response to investment, and face increasing marginal costs of violence due to opportunity costs and gratitude, so that holding enforcement and service provision constant, the $v^{*}$ curve is downward sloping. (If we additionally account for the indirect effects of investment, through increased enforcement and service provision (proposition \#8), the unconditional $v^{*}$ curve will have an even steeper downward slope, as enforcement and service provision both depress violence (proposition \#7).) In the context of Table 1, that assumption would resolve both ambiguous signs in the slopes of best response functions.

[Insert Figure 5 about here.]

Thus, since the $I^{*}$ curve and the $v^{*}$ curves are both downward sloping, a shift in either should generate a negative correlation between investment and violence, under the assumption of no

\footnotetext{
${ }^{13}$ Rebel violence might dissuade investment for other reasons as well, including risk aversion by investors. That extension would not alter the basic logic of the model.
} 
predation. Should the source of variation be factors that shift violence, such as norms of cooperation with rebels, availability of weapons, or the like, then shifts in the $v^{*}$ curve will trace out a downward sloping $I^{*}$ curve, which would imply a negative correlation of investment and violence, as in Kapstein and Converse (2008). On the other hand, should the source of variation be investment opportunities, due to changes in prices of inputs or outputs for instance, these would shift the $I^{*}$ curve, which would map out the downward sloping $v^{*}$ curve. Either way, a lack of rebel predation implies a negative correlation of investment and violence, an implication we can test with data.

We turn now to data and results, returning to these comparative statics in our discussion.

\section{Data}

To test these theories, we match data on industrial building permits to violent incident data, for eighty Philippine provinces between 2002 and 2008. Descriptive statistics are provided in Table 2. Building permits data are from the National Statistics Office of the Philippines website. ${ }^{14}$ Industrial buildings permits have a price increasing in the value of investment. The provincial average is 65 PHP per capita. Population data are from the Philippines National Statistics Office for the 2000 and 2007 Census. Provinces averaged 2.6m inhabitants over the sample period, which is skewed by the national capital region, at $11.5 \mathrm{~m}$.

Data on violence come from original incident reports generated by deployed units in the Armed Forces of the Philippines (AFP) between 2002 and 2008. The resulting dataset is a complete set of information from every such incident reported to the AFP's Joint Operations Center (JOC). Specifically, the data include information on date, location, initiator (government, insurgent group), casualties, and the type of casualty (government, insurgent, civilian). These data are an invaluable source of information for empirical analysis of violence (Felter 2005; Crost, Felter and Johnston

14 http://www.census.gov/ph/data/sectordata/databldgperm.html, accessed November 9, 2011. 
2012). The AFP reports an average of 0.29 incidents per 10,000 residents per province-year, of which about two thirds are government initiated. Rebel initiated incidents account for fifty-five percent of fatalities, averaging 0.054 fatalities per 10,000 residents per province-year, while government initiated incidents average $0.044 .{ }^{15}$ Since the identity of fatalities in irregular warfare is subject to biases we will concentrate our analysis on the identity of the initiator, which we think is reported more accurately.

One concern with incident data is that more troops may simply imply more complete reporting. That would bias our estimated correlation of investment and violence in a positive direction. Berman et al (2013) find no evidence of such a bias when estimating the effects of CERP programs in IRAQ, when augmenting their estimating equation with a measure of troop strength. Crost, Felter and Johnston (2012) conduct a robustness test for bias due to troop strength by measuring effects on violence in neighboring regions and find no evidence of bias. ${ }^{16}$

\section{Violence and Investment in the Philippines: What Do the Data Say?}

The rich data available on insurgent-related violence in the Philippines allow us to test the competing theories linking economic activity to violence, in the context of our omnibus model. We begin by restating our discussion of the spatial correlations in the cross-section, as illustrated in Figure 1. We then proceed to examine the correlations of changes in investment with changes in different measures of enforcement (i.e., government-initiated political violence), and finally to the

\footnotetext{
${ }^{15}$ Almost half of fatalities reported for rebel initiated incidents are among government forces (0.033), while $39 \%$ of reported fatalities in rebel initiated incidents (0.026) are civilians. Seventy-eight percent of fatalities reported in government initiated incidents are among rebels, while eighteen percent are among government forces and four percent are among civilians.

${ }^{16}$ Crost, Felter, and Johnston (2012) also express a second concern with these data. AFP units may selectively misreport casualties, exaggerating damage done by rebel groups and understating that done by their own units. This is a lesser concern for us, as our results (below) will turn out to be robust across measures of violence and hold for overall fatalities -which are less susceptible to misreporting. In any case, information gathered for Felter (2005) and Crost, Felter, and Johnston (2012) suggest that strong institutional incentives mean the magnitude of such selectivity is likely small. The JOC relies on accurate reporting to plan future operations. Any misreporting could mean risking the lives of AFP units.
} 
correlations of changes in investment with changes in rebel violence. Since we lack a source of exogenous variation we cannot infer a causal relationship from correlations alone, so we will lean heavily on the model.

Table 3A reports results using all 560 province-years available to use for analysis, covering the period 2002 through 2008. Column (1) reports the coefficient from a cross-sectional regression of incidents $(m+v)$ on industrial building permits which pools the 560 observations. The coefficient is negative and highly statistically significant, reflecting again the pattern we observed in Figure 1: violence and investment have a negative spatial correlation. Revisiting our interpretation of that spatial correlation, in light of the full set of predictions reported in Table 1: norms favoring rebels are more common in the sparsely populated provinces and in the Muslim majority provinces of Mindanao (anecdotally); those norms predict higher violence $\left(\mathrm{dv}^{*} / \mathrm{dn}>0\right.$, column two, row one) and lower investment if extortion exceeds taxation $(\mathrm{dI} * / \mathrm{dn}<0$, column four, row one); rebel violence also predicts high government violence $\left(\mathrm{dm}^{*} / \mathrm{dv}>0\right.$, column three, row two). Note that the spatial predictions for investment and government enforcement are ambiguous in the model, so that the data reveal two insights: first, it's likely that extortion rates exceed taxation rates, so that investment declines rather than increases in norms favoring violence (proposition \#4); second, enforcement reacts more to rebel violence (proposition \#5) than it is dissuaded by norms (proposition \#3), and does not completely reverse the norm-induced increase in rebel violence (proposition \#6). The model has used norms as a proxy for all time-invariant characteristics of provinces, which more broadly might include terrain, infrastructure, access to markets, effectiveness of service provision by government relative to that by rebels, and other persistent factors.

The most important conclusion for a discussion of investment is that the spatial pattern of investment and violence suggests that firms perceive taxation as preferable to predation when investing -otherwise they would invest more in rebel-influenced areas. In the narrow context of the 
model that is a statement about rates. A broader interpretation might be that firms prefer the predictability and low risk associated with government control over a more arbitrary and potentially violent predatory system of extortion.

We turn now to an analysis of changes in investment and political violence. The advantage of analysis of changes is that when persistent factors are held constant the effect of innovations may be revealed.

Consider an estimating equation relating enforcement to investment. While the spatial (i.e., cross-sectional) correlation of enforcement and investment is negative, as we have seen, it includes the effects of persistent factors such as norms, and may also include some trends. Hopefully, by estimating (6) in changes we can remove the effects of persistent factors and trends we can recover the coefficient $b$, which reflects the effects of changes in investment on changes in enforcement, and vice versa, as derived in propositions \#7 and \#8.

$$
m_{i t}=a\left(n_{i}\right)+b I_{i t}+d_{t}+e_{i t}
$$

Recall that, as illustrated in Figure 4, the model predicts that $b$ is positive: enforcement increases in investment because the returns to enforcement increase in tax revenue available; investment increases in enforcement if extortion rates exceed taxation rates (as we inferred from Figure 1 and from the negative spatial correlation of incidents and investment in column (2)) because enforcement increases the probability of government control, and net returns to investment are higher in government controlled areas.

Table 3A reports estimates of $b$ in columns (3) through (7) for various measures of enforcement, including government initiated incidents, total fatalities in government initiated incidents, and, of those, for fatalities among government forces, rebels and civilians. (Coefficients are estimated using a first-differenced specification, rather than fixed-effects, because the residual is nonstationary in levels, as the note to the table explains.) Coefficients are statistically significant and 
positive for total fatalities (column 4), government fatalities (column 5) and rebel fatalities (column 6). The correlation of total fatalities and investment is illustrated in the left panel of Figure 7, with each dot representing a change in both building permits and fatalities in a province over a one year period. Table 3B reflects estimates of the same coefficient for the subsample excluding Zambales (which is an outlier with a spike in investment and a moderately large population of about 700 thousand). Results are qualitatively the same though with smaller t-ratios.

Overall the data tell a clear story about enforcement and investment: while these two variables are negatively correlated spatially, changes in investment are positively correlated with changes in enforcement, as illustrated in Figure 4. We can't make a causal inference for lack of exogenous variation, but we can conclude that either enforcement increases in investment -an unambiguous prediction of the model due to the taxation effect, or investment increases in enforcement -which the model predicts if extortion rates exceed taxation rates so that investors prefer government control. Or both.

Conversely, in the context of the model, the data reject that two conditions are simultaneously true: that investors are indifferent as to who controls territory -rebels or government, and that government is indifferent to investment (strictly speaking, to tax revenue) when making enforcement decisions.

We now turn to the correlation of changes in investment with changes in rebel violence, which can shed light on core questions of economic development in insecure environments. Hypotheses about predation, opportunity costs, gratitude and taxation would all be expressed in this correlation. We know from Figure 1 that investment is negatively correlated with violence spatially, which might suggest that investment reduces violence, or that predictable violence reduces investment. Yet that correlation potentially reflects persistent effects such as attitudes towards rebels, which plausibly both increase rebel violence and depress investment. To clarify, equation (7) 
defines a linear coefficient $k$ relating investment to rebel violence which holds time-invariant factors and secular trends constant. This is equation mirrors (6), but with rebel violence v instead of government enforcement $m$ on the left hand side.

(7) $\quad v_{i t}=h\left(n_{i}\right)+k I_{i t}+l_{t}+u_{i t}$

Recalling the discussion of Figure 5, if predation were entirely absent then $k$ should be negative. On the one hand, rebel violence should decline in investment without predation, as investment attracts enforcement. Opportunity cost and gratitude effects would only make that slope steeper. On the other, investment should decline in rebel violence in the absence of predation, since the taxation rate would exceed the extortion rate (of zero) and rebel violence would tend to deliver the territory to government, implying higher expected investment taxes.

Turning to the right panel of Table $3 \mathrm{~A}$ we see that the regression of changes in measures of rebel violence on changes in industrial building permits are not terribly informative. All five measures are positive, in columns (8)-(12), but only one is marginally significant (at the $10 \%$ level). The evidence in Table 3B, which excludes the large outlier province of Zambales, is clearer. All five coefficients are again positive, with coefficients statistically significant at the $5 \%$ level for both the rebel-initiated incident count and for civilian casualties from those rebel-initiated incidents.

The data clearly reject the conclusion that predation is entirely absent.

As discussed above, a possible explanation for these positive correlations of violence with investment is that investment induces troop presence, which in turn generates more reporting of incidents by construction. We think that this is unlikely, based on the authors' experience with similar data in other countries, where measures of troop presence did not affect results (Berman et al., 2013). Following Crost, Felter and Johnston (2012) we also provide a robustness test. Deploying more troops to one province requires taking some away from another. If in a given province 
increased troop strength creates more reported incidents by construction, then reported violence might decline in neighboring provinces. We test this hypothesis and find no evidence of spillovers. ${ }^{17}$

Our model admits some ambiguity about timing. Though in the model firms, rebel and government act simultaneously, we would like to admit the possibility that firms' investment begins earlier, as it requires longer lead time (though retaining the ability of firms to predict future violence, which is key to the predictive investment hypothesis). Following that logic would indicate an estimating equation in which past investment predicts current violence, where the interpretation could be predation, tax capture, predictive investment, opportunity costs or gratitude.

Results of estimating that equation are reported in Table 4A, which retains the same format as Table 3, but with last year's value of building permits on the right hand side rather than a concurrent value. The surprise in this table is that last year's investment predicts a decline in current enforcement of about the same magnitude as the concurrent increase we saw in Table $3 \mathrm{~A}$. That decline is highly statistically significant for all fatalities, government fatalities and rebel fatalities. If we continue to follow the logic that government response requires a year, then that result contradicts the clear predictions of the model in propositions \#7 and \#8. In general equilibrium enforcement could decline as an indirect response to investment if investment caused rebel violence to decline, which in turn reduced necessary enforcement (proposition \#5). Yet the right panel of Table 4A shows no response of rebel violence to lagged investment either. An alternative interpretation is that the data request a dynamic model, in which one period of enforcement is sufficient to deter future rebel violence (perhaps by signaling capacity or commitment) so that the optimal enforcement response need not last more than a year.

\footnotetext{
${ }_{17}$ We estimate the specification in Table 3 using permits in province $i$, year $t$ and average violence in other provinces in the same geographic region in year $t$. There are seventeen such regions in the Philippines. The resulting coefficients are either statistical zeros, or positive. Results available upon request.
} 
The right panel of Table 4A also carries another message. Like current investment, lagged investment shows no evidence of a negative correlation with violence, providing no supporting evidence for predictive investment, opportunity cost or gratitude mechanisms. Table $4 \mathrm{~B}$ repeats the analysis for the sample excluding Zambales province, reporting essentially the same results.

\section{Discussion}

How can we interpret the regression results in terms of the underlying model? So far we've seen evidence consistent with both a "tax-capture" effect for government and a predation-avoidance effect for firms: a positive correlation of government enforcement with investment. We can also reject the comparative statics of the "no predation" case in Figure 5, since rebel violence and investment are positively correlated.

Yet the positive correlation of violence and investment is open to multiple interpretations, as theory allows both an upward sloping $v^{*}$ curve and an upward sloping $I^{*}$ curve in $v-I$ space. Perhaps investment increases violence, as the predation effect dominates through a higher extortion rate, or violence increases investment, as the incidence effect dominates, or both? Proposition \#11 was of some help, showing that both curves cannot be simultaneously upward sloping, yet it could not determine which one actually is.

Figure 6 illustrates one possible interpretation of the positive correlation of violence and investment: rebel violence optimally increases in investment, while investment declines in violence. In that case variation in investment opportunities shifts the $I^{*}$ curve along an upward sloping $v^{*}$ curve, plotting a positive correlation.

Based on theory alone, we cannot rule out the other possibility, that the positive correlation between investment and violence in the data is due to an upward sloping $I^{*}$ curve traced out by shifts in a downward sloping $v^{*}$ curve (the opposite slopes to those drawn in figure 5). We think that this is unlikely for three reasons. First, for optimal investment to increase in violence the rebel 
extortion rate must exceed the government taxation rate (as implied by proposition \#9), which seems unlikely at the low levels of violence we observe in many provinces. Second, that assumption is inconsistent with the negative spatial correlation of investment and violence that we saw in Figure 1 and in Table 3. Third, Crost, Felter and Johnston (2012), find that the announcement of a forthcoming government sponsored community driven development project in rural Philippine municipalities predicted increased rebel violence. That would imply an upward sloping $v^{*}$ curve, which in turn implies a downward sloping $I^{*}$ curve, by proposition \#11, as illustrated in Figure 6.

Moreover, if we accept the inference that violence increases in investment, that triggers a further inference, that neither incidence effects, an opportunity cost mechanism, or a gratitude mechanism can be the dominant force in play in the rural Philippines.

A further implication of an upward sloping $v^{*}$ curve is that government enforcement is optimally increased in response to investment, not only conditionally on $v$ (as in proposition \#7) but also unconditionally, since increased violence induces increased enforcement (proposition \#3) directly, so that increased investment induces increased enforcement both directly and indirectly, through its effect on violence. That stronger analytical prediction is consistent with the evidence in Table 3.

\section{When does predation dominate?}

Our results are consistent with predation, which roughly accords with some of the literature on subnational violence, but not with all of it. Why is predation sometimes the dominant mechanism, but not always? The answer is relevant to the design of development programs in conflict-cursed environments where rent capture is a possible motivation for violence. Before concluding we attempt to reconcile the literature as it stands, in light of the omnibus model developed above. 
A first step is to take stock of the recent literature, which has developed quickly. This is not the first paper to find a positive correlation between a measure of economic activity and violence at the subnational level. Berman, Shapiro, Felter and Callen (2011) found that employment rates and violent incidents were positively correlated in Iraq, Afghanistan and the Philippines during periods in which each of those countries were experiencing active insurgencies during this century. Dube and Vargas (2010) looking at Colombian data, found that increases in natural resource prices, particularly oil, predicted increased violence in regions that had significant natural resource extraction. As mentioned above, Crost, Felter and Johnston (2012) find that development projects in rural Philippine municipalities predicted increased violence. Nunn and Qian (2012) find that U.S. food aid increases the incidence of civil conflict among recipient countries. These findings should cause concern for development practitioners. They are consistent with our conclusion from the Philippine data: an optimal violence curve by rebels which is upward sloping in investment in particular, or in economic activity in general.

On the other hand, we are aware of multiple cases in which subnational variation in economic activity predicts reduced violence. For example, Miguel, Satyanath, and Sergential (2004) found that economic activity induced by rainfall was associated with declines in violence. Dube and Vargas (2010) show that in Colombia increased prices for agricultural goods, particularly coffee, predict reductions in violence, a result that they interpret as an opportunity cost mechanism. BSF find that small scale reconstruction program spending by the US military in Iraq was violencereducing, which they interpret as evidence for a mechanism of information (tip) provision by noncombatants to forces allied with government. (That interpretation is supported by evidence from Shapiro and Weidmann (2011), who show that cellphone coverage -a plausible conduit for information provision by noncombatants—is associated with reduced insurgent violence during the Iraq war.) Hanson, Iyengar, and Monten (2011), studying spending on labor in general 
reconstruction programs in Iraq (not just CERP), also find a violence reducing effect. Crost, Felter and Johnston (2012) have presented preliminary results indicating that conditional cash transfers (under the government's Pantawid Pamilyang Pilipino Program) have a small but significant violence reducing effect in Philippine communities.

How then to reconcile these conflicting results? Two aspects of our model might be helpful. The first is conditionality, which, as first introduced in BSF, implies that continued receipt of development assistance is conditioned on recipients (individuals or community) not cooperating with rebels. Conditionality is an aspect of the implementation of the CERP program which BSF found to be violence-reducing in Iraq. Whether the employment spending in the programs analyzed by Hanson, Iyengar, and Monten (2011) was conditional is unclear. The conditional cash transfer program which was violence-reducing in the Philippines also insisted that members of families receiving cash transfers not engage in any illicit or unlawful activities to include cooperating with rebels. Conditionality in this case was both directly and indirectly enforced by mandatory attendance at weekly meetings with assigned monitors tasked with insuring compliance of beneficiaries with program requirements (Crost, Felter and Johnston, 2012). Conditionality would presumably not have been present in the mechanisms that cause investment to vary in the Philippines in this paper, or employment rates to vary (in Iraq, Afghanistan and the Philippines) in Berman et al (2011). Likewise, there would be no conditionality present in the variation of oil prices in Colombia in Dube and Vargas' (2010) data. Careful study of the Crost, Felter, and Johnston (2012) results indicate that the Kapit-Bisig Laban sa Kahiripan - Comprehensive Integrated Delivery of Social Services (KALAHI-CIDSS) - the community driven development program in the Philippines- did not condition program receipt on noncooperation. Thus the absence of conditionality can explain all of the four negative results, and the presence of conditionality can explain two of the four positive results, the exception being Dube and Vargas' findings that increased wages reduce violence in coca 
growing parts of Colombia. The hypothesis would be agnostic on the Hanson, Iyengar, and Monten (2011) results.

A second helpful concept, which may also help explain the apparently contradictory results, is the extortability of economic rents, an idea developed by Collier and Hoeffler (2004). In the two cases in which conditionality was imposed, the CERP program in Iraq and the conditional cashtransfer program in the Philippines, the presence of a capable coercive force that could enforce conditionality might also prevent predation by rebels. Turning to the cases in which conditionality is absent, it might be that wages are less vulnerable to extortion than are oil revenues in rural Colombia (in Dube and Vargas, 2010) or than real estate investments in the Philippines, in this paper. Taking the extortable rents approach would then explain all three of the four positive cases (in which violence is negatively correlated with increased economic activity), with the exception being Miguel, Satyanath, and Sergenti (2004) and the prediction for the Hanson, Iyengar, and Monten (2011) results being unclear. Extortable rents would also explain three of the four negative results, the possible exception being the Berman et al (2011) finding of a positive correlation of employment rates and violence in three countries, where it is unclear whether variation in employment represents variation in extortable economic activity.

A separate subnational result is what we have termed the "predictive investment" mechanism in Besley and Meuller (2012), in which the expectation of reduced violence increases the value of investments in Northern Ireland. While that result belongs in the literature on subnational correlations between violence and economic activity, (and fits easily in our model) it does not help address the puzzle of why economic activity (as opposed to the expectation of it) is sometimes associated with increased violence, and sometimes with its decrease.

A tentative practical conclusion from this recent literature is this: in addition to the standard conditions required for development programs to be effective in secure environments, two sufficient 
conditions for programs to be violence-reducing in insecure spaces are these: First, economic gains must be conditional on noncooperation with rebels and second, these gains must not create easily extortable rents. These extra conditions clearly bring with them ethical tradeoffs between different aspects of human welfare, forcing a choice between improving economic wellbeing and possibly strengthening rebel groups (or criminal elements) through extortion of economic activity. An important topic for future research would therefore be to discover whether both conditionality and non-extortability are necessary conditions.

\section{Conclusions}

Some governments, and their allies, have turned to economic programs alongside other instruments as part of their strategy to reduce insurgent violence. Underlying this approach is often a view, sometimes vaguely articulated, that once a degree of prosperity is achieved, people will become hopeful about the future, making political choices that in turn spur stability and economic growth. Growth might become self-reinforcing should it increase the opportunity cost of violence for insurgents and motivate noncombatants to cooperate with government in its efforts to expel rebels. Recent studies have attempted to develop a theoretical underpinning of this political economy of improved governance, along with empirical tests of different theoretical relationships. Yet about half of the empirical studies at the subnational level are inconsistent with the coarse hypothesis that all economic activity will be violence-reducing under all conditions.

This paper examined the connection between investment, rebel violence, and government enforcement, expanding existing theory of counterinsurgency to a four-sided game, including for the first time firms who make investments, rebel predation on investment, and government taxation. This model includes the possibility that investment predicts violence. In the context of the model, the data yield a number of findings. Most importantly, we reject a model that does not include some measure of predation. Our findings are also consistent with the idea that predation is the dominant 
mechanism linking investment to rebel violence, rather than opportunity costs, gratitude or predictive investment. The data are consistent with government enforcement increasing in investment, or an alternative that investment increases in enforcement. Multiple findings suggest that investors prefer regions controlled by government to those controlled by rebels.

In the context of the larger literature we suggest that these results underline the importance for program design in understanding the channels that link development programs to rebel violence. We add to a recent body of evidence indicating that increases in economic activity are just as often violence increasing as they are violence decreasing. Our reading of that literature, in light of the model developed in this paper, is that two factors may be sufficient to generate a violence-reducing effect: first, limiting the extortability by rebels of economic rents generated, and second, conditioning access to the economic benefits from those programs to communities and individuals that cooperate with government. Exploring whether either of those conditions is individually sufficient, perhaps in the context of the omnibus theory developed here, presents the next challenge for future research. That research, we would argue, is not just of scholarly interest but of real policy import as well. 


\section{References}

Akerlof, George and Janet L. Yellen. "Gang Behavior, Law Enforcement, and Community Values.” In V alues and Public Policy, ed. Henry J. Aaron, Thomas E. Mann, and Timothy Taylor. Washington, DC: Brookings, 1994.

Berman, Eli, Jacob N. Shapiro and Joseph H. Felter. "Can Hearts and Minds be Bought? The Economics of Counterinsurgency in Iraq.” Journal of Political Economy 119 (2011): 766-819.

Berman, Eli, Jacob N. Shapiro, Joseph H. Felter and Michael Callen, “Do Working Men Rebel? Insurgency and Unemployment in Afghanistan, Iraq, and the Philippines," Journal of Conflict Resolution 55 (2011): 496-528.

Berman, Eli, Joseph H. Felter, Ethan Kapstein, and Erin Troland. "Predation, Economic Activity and Violence: Evidence from the Philippines,” NBER WP \#18375 (2012).

Berman, Eli, Joseph H. Felter, Jacob N. Shapiro, and Erin Troland. "Modest, Secure and Informed: Successful Development in Conflict Zones." American Economic Review, Papers and Proceedings 103 (2013): 512-517.

Besley, Timothy and Hannes Mueller. "Estimating the Peace Dividend: The Impact of Violence on Housing Prices in Northern Ireland.” American Economic Review 102 (2012): 810-33.

Blattman, Christopher and Edward Miguel. "Civil War." Journal of Economic Literature 48 (2010): 3-57. Brückner, Markus and Antonio Ciccone. "Rain and the Democratic Window of Opportunity." Econometrica 79 (2010): 923-947.

Chaney, Eric. “Assessing Pacification Policy in Iraq: Evidence from Iraqi Financial Markets.” Journal of Comparative Economics 36 (2008):1-16.

Chaney, Eric. "Revolt on the Nile: Economic Shocks, Religion, and Institutional Change.” Working paper, Harvard University, 2010. 
Collier, Paul. "Rebellion as a Quasi-Criminal Activity." The Journal of Conflict Resolution 44 (2000): 839 853.

Collier, Paul and Anke Hoeffler. "Greed and Grievance in Civil War.” Oxford Economic Papers 56 (2004): 563-595.

Coyne, Christopher, Gregory Dempster and Justin Isaacs. "Asset Values and the Sustainability of Peace Prospects." Quarterly Review of Economics and Finance 50 (2010).

Crost, Benjamin, Joseph H. Felter and Patrick Johnston. “Aid Under Fire: Development Projects and Civil Conflict.” Mimeo, U. of Colorado, Denver, 2012.

Dube, Oeindrila and Juan Vargas. "Commodity Price Shocks and Civil Conflict: Evidence from Colombia.” Manuscript, New York University, 2010.

Felter, Joseph H. “Taking Guns to a Knife Fight: A Case for Empirical Study of Counterinsurgency.” PhD diss., Stanford University, 2005.

Fearon, James D. "Why Do Some Civil Wars Last So Much Longer Than Others?” Journal of Peace Research 41 (2004):275-302.

Fearon, James D. "Economic Development, Insurgency, and Civil War.” Manuscript, Stanford University, 2007.

Fearon, James. "Economic Development, Insurgency, and Civil War.” In Institutions and Economic Performance edited by Elhanan Helpman. Cambridge: Harvard University Press, 2008.

Fielding, David. "Modelling Political Instability and Economic Performance: Israeli Investment During the Intifada.” Economica 70 (2003):159-86.

Fishstein, Paul, and Andrew Wilder. "Winning Hearts and Minds? Examining the Relationship between Aid and Security in Afghanistan.” Mimeo, Tufts University, 2012.

Government of the Philippines, National Statistics Coordination Board. n.d.

Gradstein, Mark. “Governance and Growth.” Journal of Development Economics 73 (2004):505-518. 
Grossman, Hershel. "Kleptocracy and Revolutions.” Oxford Economic Papers 51 (1999): 267-283.

Hanson, Matthew, Radha Iyengar, and Jonathan Monten. "Building Peace: The Impact of Aid on the Labor Market for Insurgents.” Working Paper 17297, National Bureau of Economic Research, 2011.

Hirshleifer, Jack. "Conflict and Rent-Seeking Success Functions: Ratio vs. Difference Models of Relative Success.” Public Choice 63 (1989): 101-112.

Hirshleifer, Jack. The Dark Side of the Force. New York: Cambridge University Press: 2001.

International Crisis Group. "The Philippines: Counter-insurgency vs. Counter-terrorism in Mindanao." Asia Report Nº152, May 14, 2008.

International Crisis Group. "The Communist Insurgency in the Philippines: Tactics and Talks.” Asia Report N²02, February 14, 2011.

Jones, Charles I. Introduction to Economic Growth. New York: W.W. Norton, 2002.

Kapstein, Ethan B. Sharing the Wealth: Workers and the World Economy. New York: W.W. Norton, 1999.

Kapstein, Ethan B. "Two Dismal Sciences are Better than One: Economics and the Study of National Security.” International Security 27 (2002):158-187.

Kapstein, Ethan B. and Nathan Converse. The Fate of Young Democracies. New York: Cambridge University Press, 2008.

Kilcullen, David. “Counterinsurgency Redux.” Survival 48 (2006): 111-130.

Kilcullen, David. The Accidental Guerrilla. New York: Oxford University Press, 2009.

Kilcullen, David. Counterinsurgency. New York: Oxford University Press, 2010.

Malkasian, Carter and Gerald Meyerle. Provincial Reconstruction Teams: How Do We Know They Work? U.S. Army War College, 2009.

Marston, Daniel and Carter Malkasian, eds. Counterinsurgency in Modern Warfare. New York: Osprey, 2008. 
Mas-Collel, Andreu, Michael D. Whinston and Jerry R. Green. Microeconomic Theory. New York: Oxford University Press, 1995.

Miguel, Edward, Shanker Satyanath, and Ernest Sergenti. "Economic Shocks and Civil Conflict: An Instrumental Variables Approach.” Journal of Political Economy 112 (2004):725-753.

Morales, Ricardo C. Perpetual Wars: The Philippine Insurgencies. Master's thesis, Naval Postgraduate School, 2003.

Nordland, Rob. “Aid Worker's Death Stirs Debate on Strategy.” New York Times, December 13, 2010.

North, Douglass C. Structure and Change in Economic History. New York: W. W. Norton, 1981.

Nunn, Nathan, and Nancy Qian. "Aiding Conflict: The Impact of U.S. Food Aid on Civil War.” Working Paper 17794, National Bureau of Economic Research, 2012.

Perkins, Dwight H., Steven Radelet, David L. Lindauer, and Steven A. Block. Economics of Development. New York: W.W. Norton, 2013.

Popkin, Samuel L. The Rational Peasant: The Political Economy of Rural Society in Vietnam. Berkeley: University of California Press, 1979.

Powell, Robert. "War as a Commitment Problem.” International Organization 60 (2006): 169-203.

Ross, Michael. "How Do Natural Resources Influence Civil War? Evidence from Thirteen Cases." International Organization 58 (2004): 35-68.

Rubin, Alissa J. and James Risen. "Costly Afghanistan Road Project is Marred by Unsavory Alliances.” New York Times, May 1, 2011.

Sambanis, Nicholas, Paul Collier, Lani Elliott, Håvard Hegre, Anke Hoeffler, and Marta ReynalQuerol. Breaking the Conflict Trap: Civil W ar and Development Policy. Washington, DC: Oxford University Press and World Bank Publications, 2003.

Sarsons, Heather. "Rainfall and Conflict.” Manuscript, Yale University, 2011. 
Shapiro, Jacob and Nils B. Weidmann. "Talking About Killing: Cell Phones, Collective Action and Insurgent Violence in Iraq.” Working paper, Princeton University, 2011.

Stubbs, Richard. "From Search and Destroy to Hearts and Minds: The Evolution of British Strategy in Malaya, 1948-1960.” In Counterinsurgency in Modern Warfare, edited by Daniel Marston and Carter Malkasian. New York: Osprey, 2008.

Svensson, Jakob. "Investment, property rights and political instability: Theory and evidence." European Economic Review 42 (1998): 1317-1341.

Tilly, Charles. From Mobilization to Revolution. Reading, MA: Addison-Wesley, 1978.

US Army. Field Manual 3-24, Counterinsurgency Field Manual. Chicago: University of Chicago Press, 2007.

US Senate. Evaluating Foreign Assistance to Afghanistan. Washington, DC: Government Printing Office, 2011.

World Bank. “A Symposium on Post-Conflict Transitions.” World Bank Economic Review 22 (2008): 1140.

World Bank. World Development Report 2011: Conflict, Security and Development. Washington DC, 2011. 
Figure 1: Population, Investment and Political Violence in Philippine Provinces

Note: Clockwise from top left: population, industrial building permits/capita, casualties from governmentinitiated violence and casualties from rebel-initiated violence.
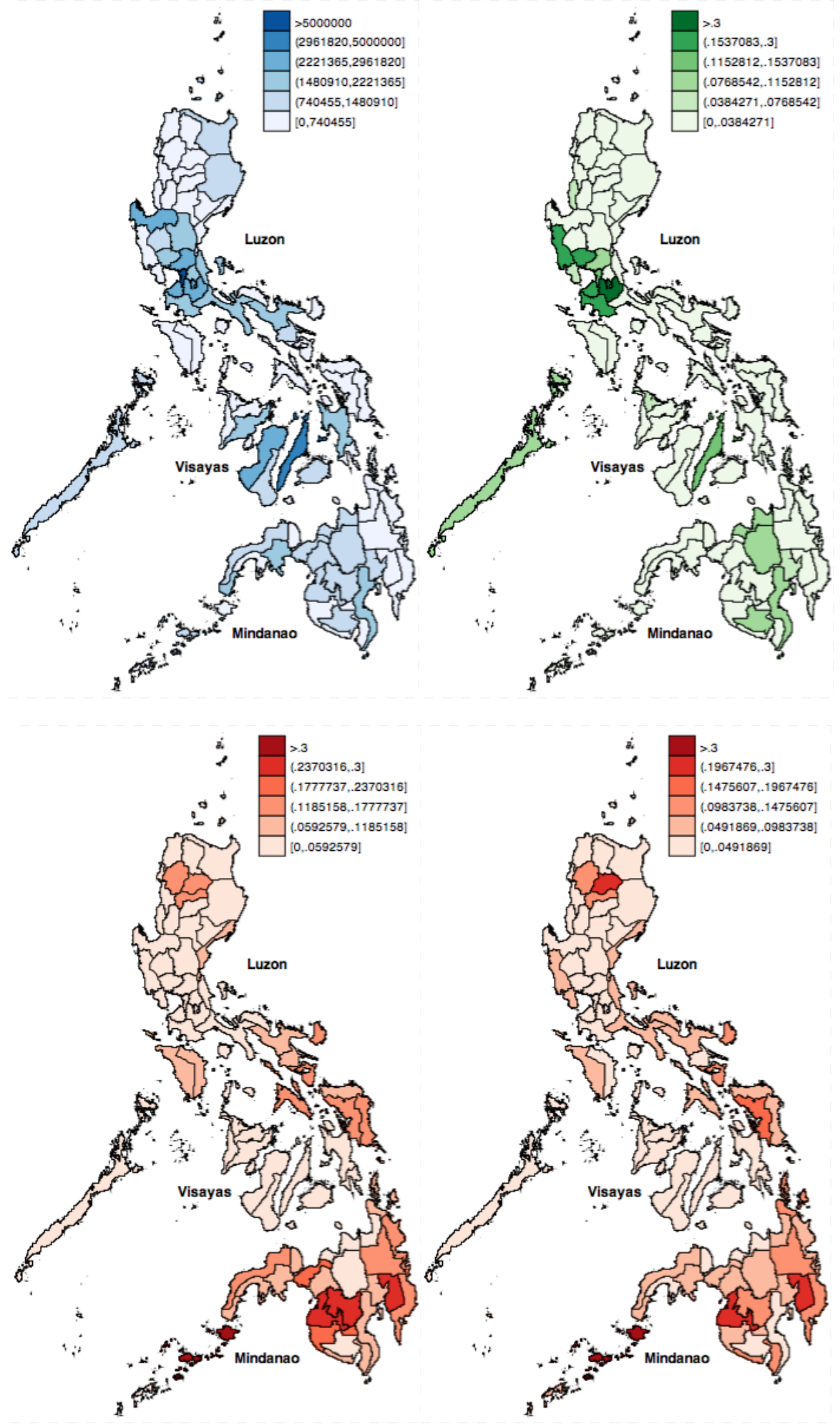


\section{FIRMS}

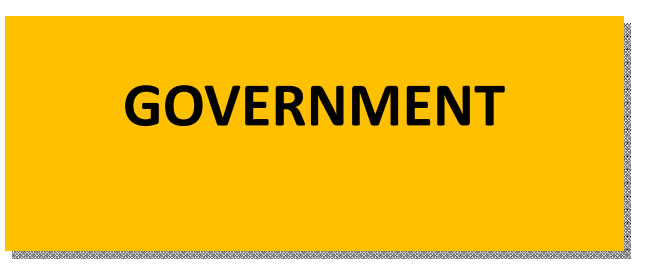

\section{REBELS}

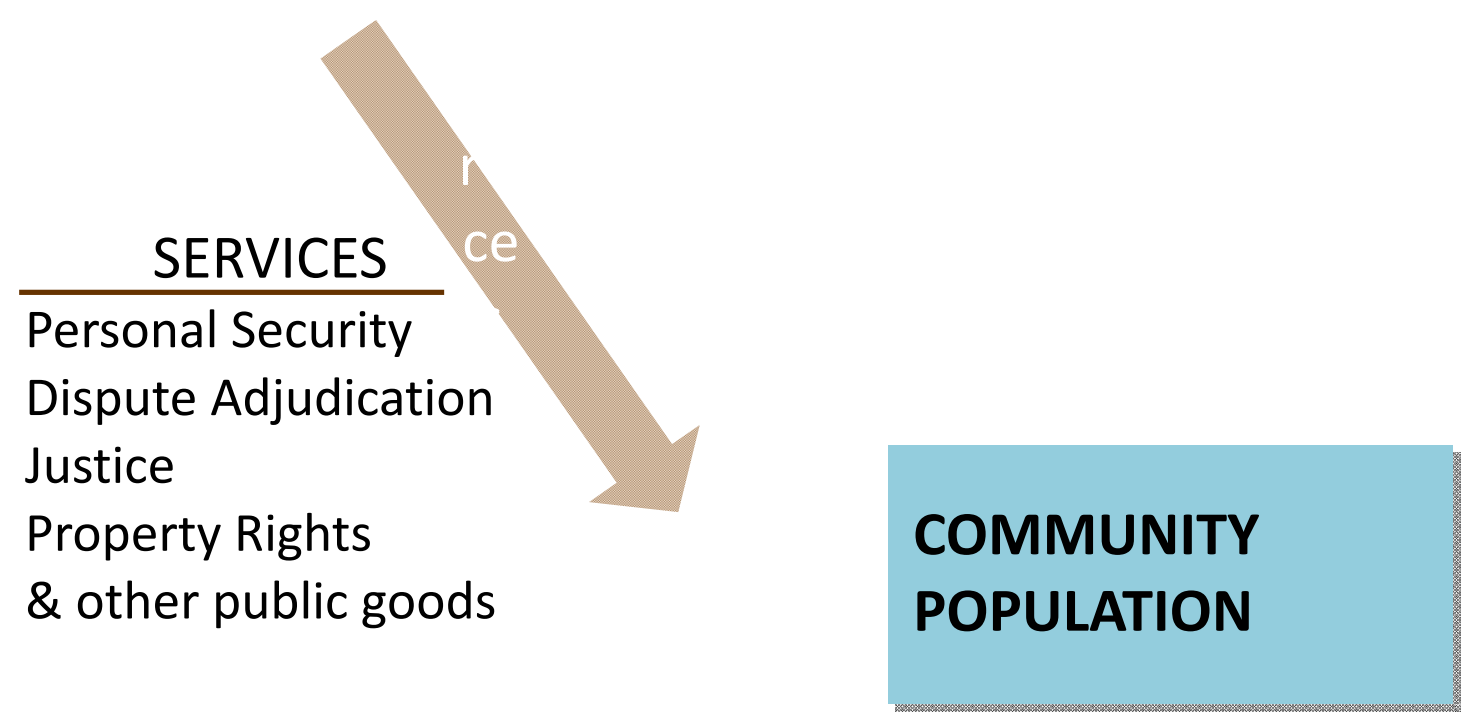


Figure 3: Utility of noncombatant community from information-sharing

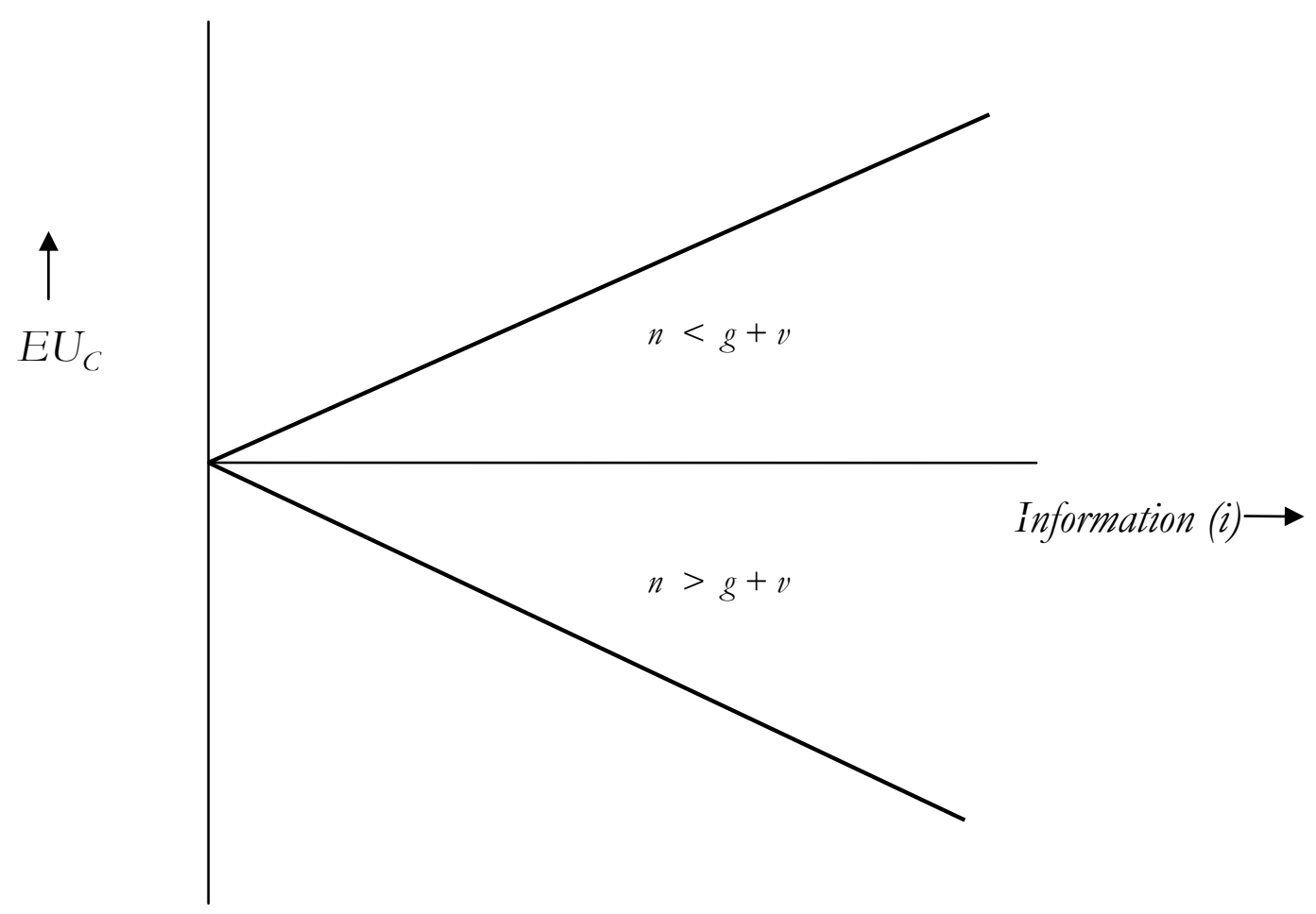


Figure 4: Best response functions for enforcement $\left(m^{*}\right)$ and investment $\left(I^{*}\right)$

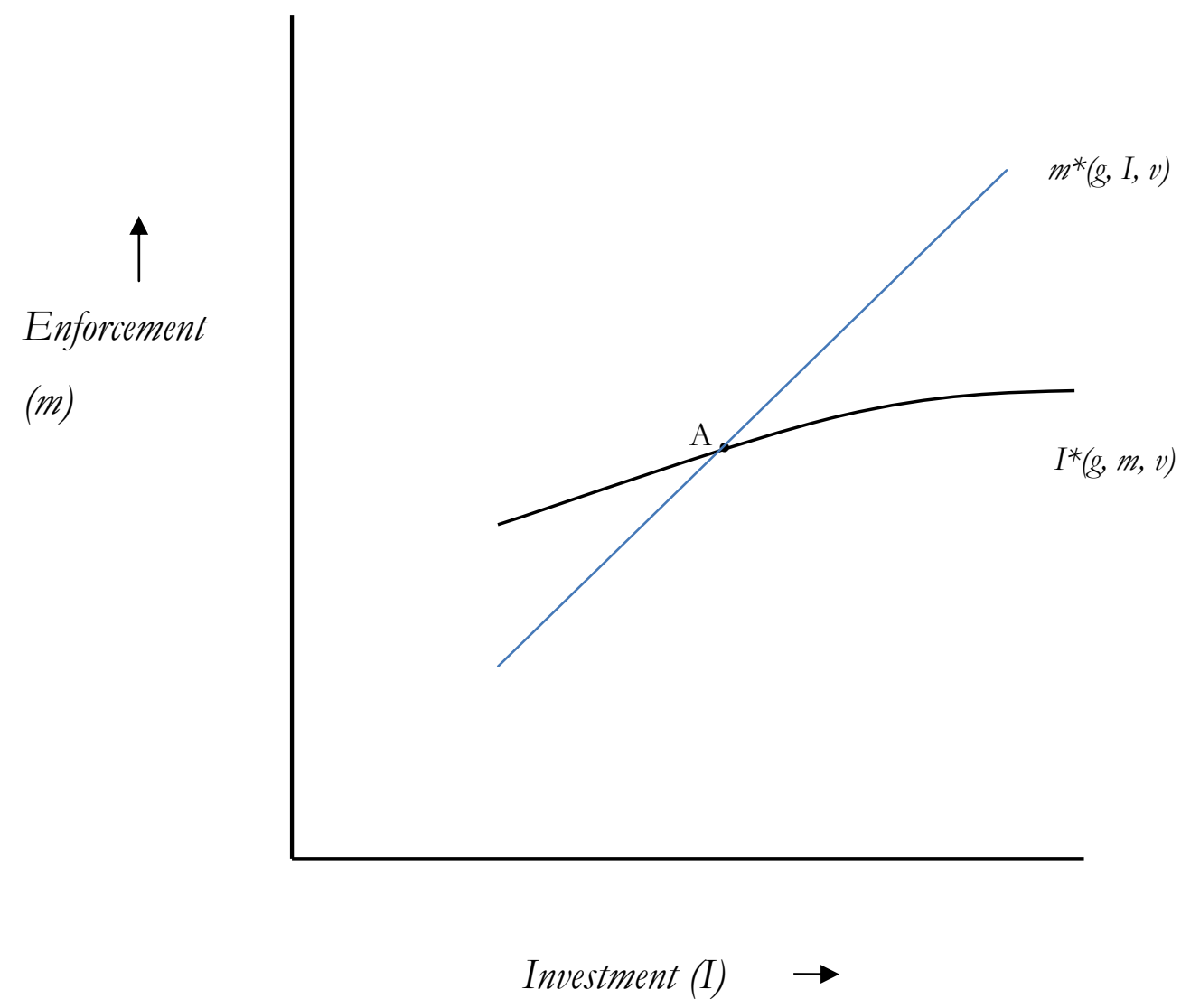

Note: The best response function for investment is drawn with a positive slope, which assumes that the extortion rate exceeds the taxation rate. 


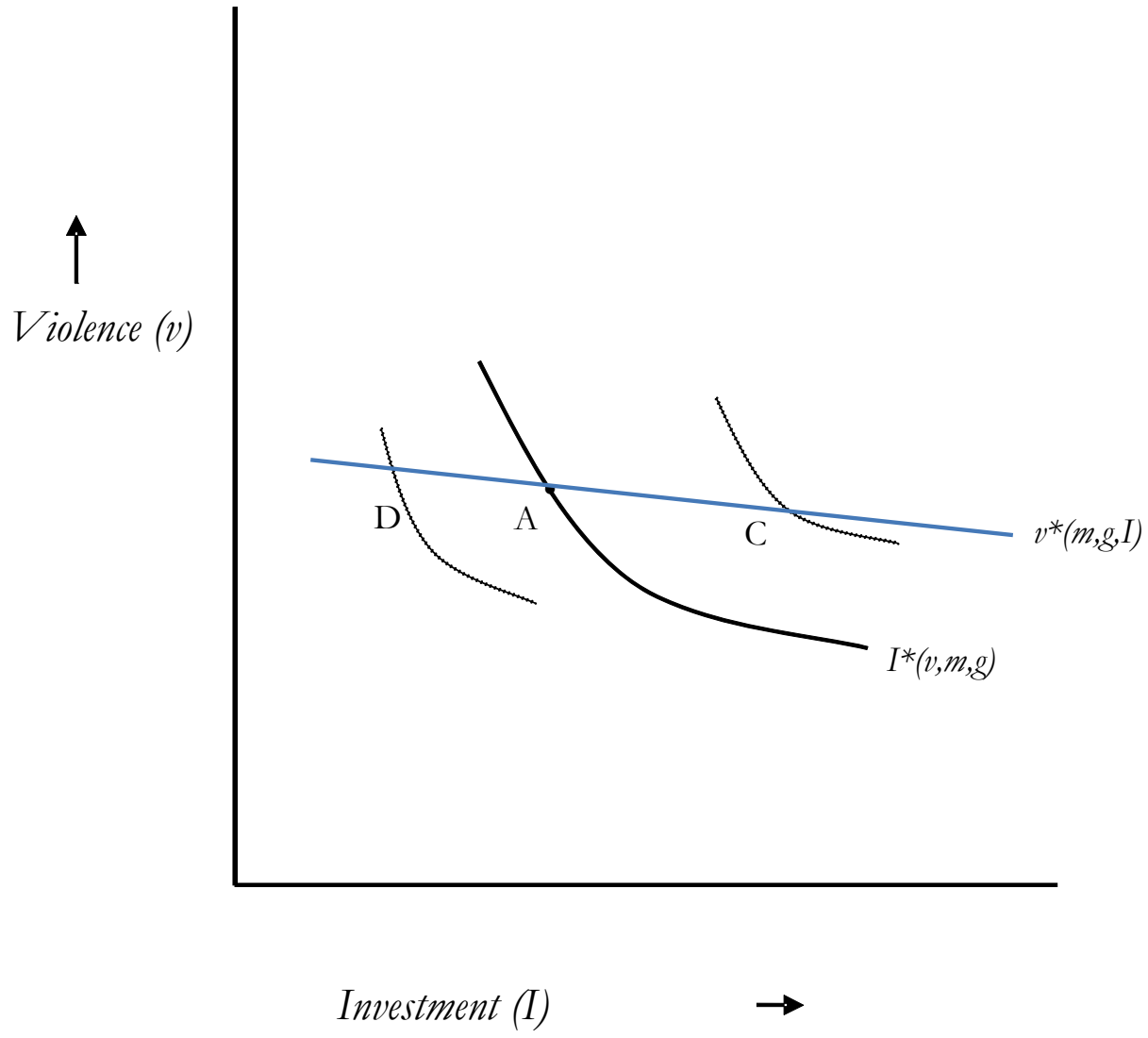

Figure 5: Best response functions for violence $\left(V^{*}\right)$ and investment $\left(I^{*}\right)$ without predation 


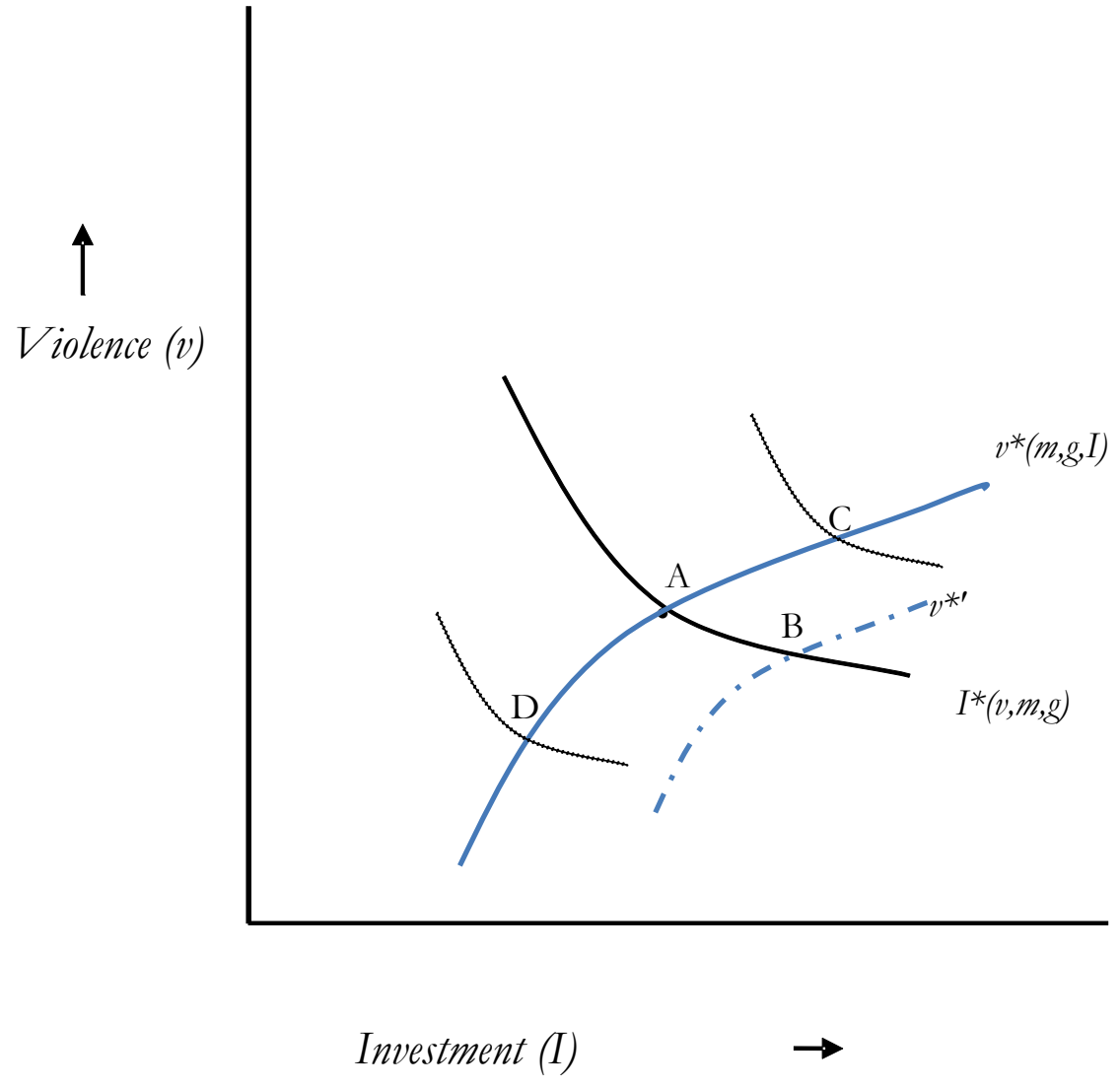

Figure 6: Investment and Violence in Equilibrium with Predation 
Figure 7: Investment and Political Violence
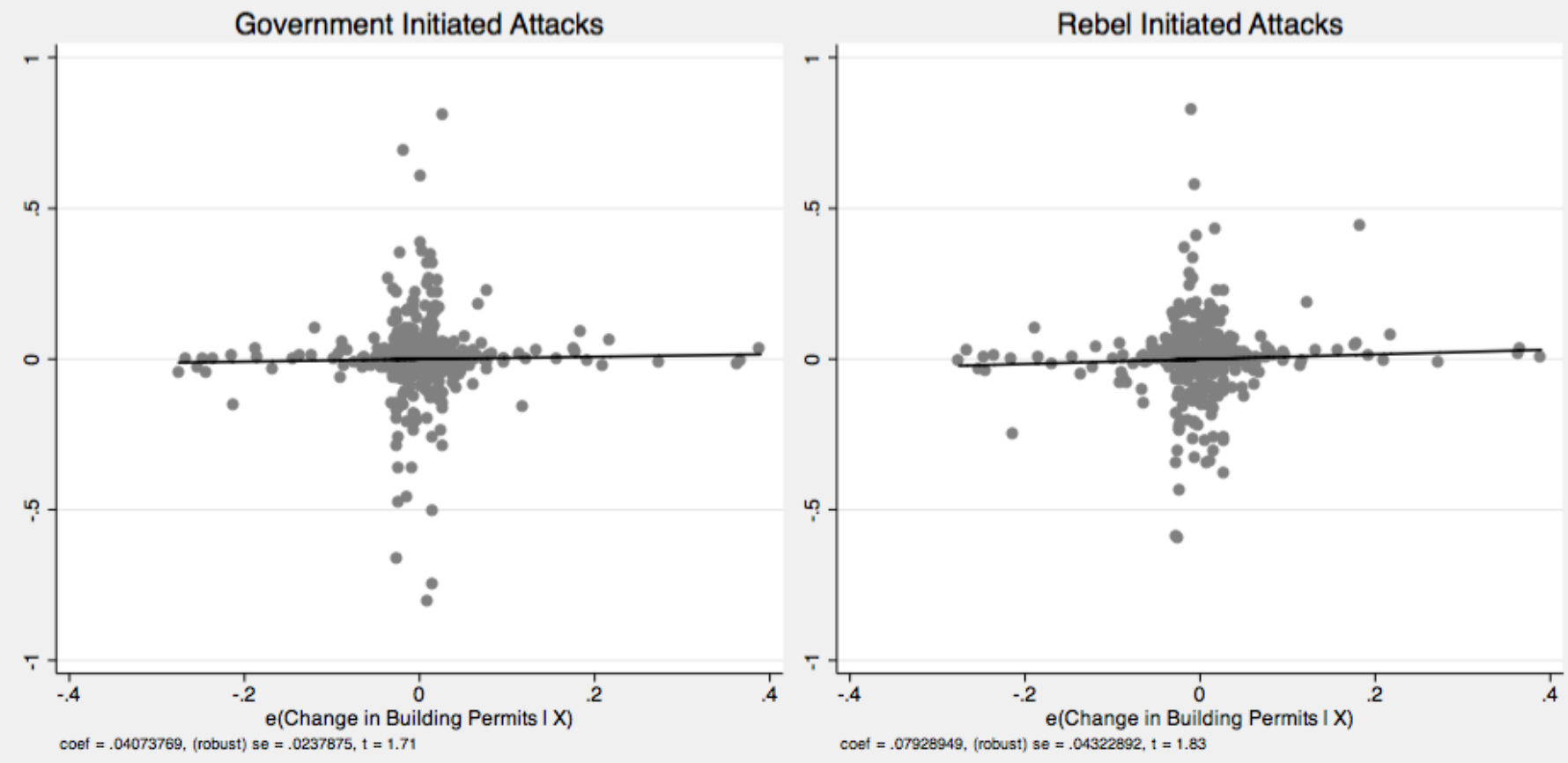
Table 1: Optimal choices

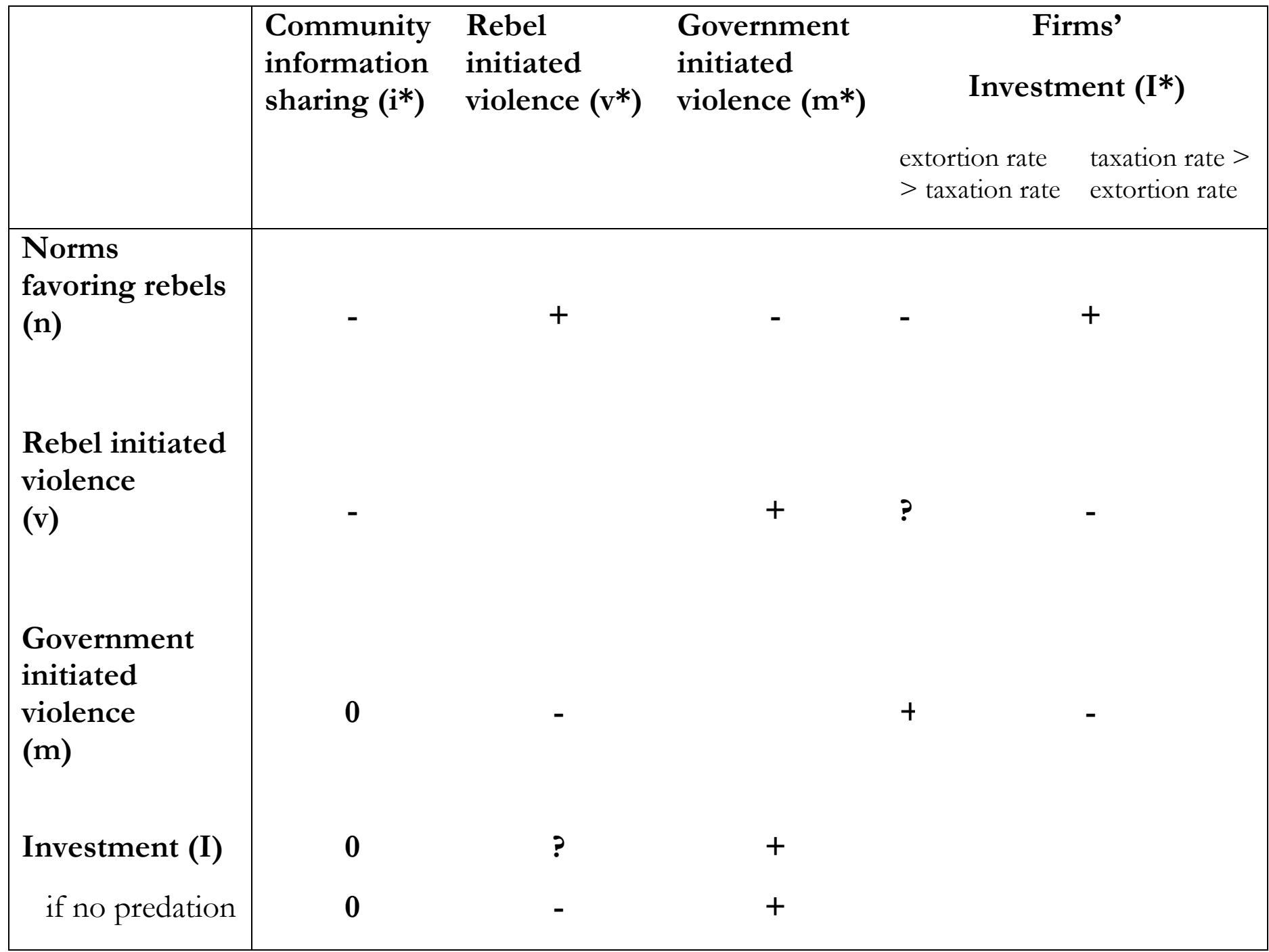

Notes: The table lists the derivatives $\mathrm{dy}^{*} / \mathrm{dx}$ of the column variables y with respect to the row variables $\mathrm{x}$, when all other row variables are held constant. For example, the top right positive sign indicates that $\mathrm{di}^{*} /\left.\mathrm{dn}\right|_{\mathrm{v}, \mathrm{m}, \mathrm{g}, \mathrm{I},}<0$. Government services $(\mathrm{g})$ are omitted for readability, as they have no direct role in the empirical analysis. Community information sharing is not listed as a row since rebels, government and firms make choices anticipating optimal response by communities in a later stage. 
Table 2: Descriptive Statistics

\begin{tabular}{|c|c|c|c|c|c|c|}
\hline & Obs & Weight & Mean & Std. Dev. & Min & Max \\
\hline \multicolumn{7}{|c|}{ LEVELS } \\
\hline Incidents / 10K & 560 & 579984131 & 0.2920597 & 0.4027358 & 0 & 4.444788 \\
\hline Govt Initiated Incidents (GI) & 560 & 579984131 & 0.1885914 & 0.2638765 & 0 & 3.232574 \\
\hline Total GI Fatalities & 560 & 579984131 & 0.0437253 & 0.094605 & 0 & 1.346906 \\
\hline Govt Fatalities & 560 & 579984131 & 0.0076726 & 0.0276077 & 0 & 0.4872676 \\
\hline Rebel Fatalities & 560 & 579984131 & 0.0343113 & 0.0740779 & 0 & 1.212215 \\
\hline Civilian Fatalities & 560 & 579984131 & 0.0017414 & 0.0086107 & 0 & 0.1195494 \\
\hline Rebel Initiated Incidents (RI) & 560 & 579984131 & 0.1018476 & 0.1734013 & 0 & 1.610619 \\
\hline Total RI Fatalities & 560 & 579984131 & 0.0543291 & 0.0969217 & 0 & 0.9267434 \\
\hline Govt Fatalities & 560 & 579984131 & 0.0267594 & 0.0539714 & 0 & 0.6771753 \\
\hline Rebel Fatalities & 560 & 579984131 & 0.0063105 & 0.0282851 & 0 & 0.7116066 \\
\hline Civilian Fatalities & 560 & 579984131 & 0.0212592 & 0.0424385 & 0 & 0.3781036 \\
\hline $\begin{array}{l}\text { Value of Industrial Building } \\
\text { Permits per Capita (PHP) }\end{array}$ & 560 & 579984131 & 0.0654696 & 0.1018505 & 0 & 1.295499 \\
\hline $\begin{array}{l}\text { Lagged Value of Industrial } \\
\text { Building Permits per Capita }\end{array}$ & 480 & 502363824 & 0.0696258 & 0.1073403 & 0 & 1.295499 \\
\hline Population & 560 & 579984131 & 2604672 & 2986180 & 15974 & $1.15 \mathrm{E}+07$ \\
\hline \multicolumn{7}{|c|}{ FIRST DIFFERENCES } \\
\hline Incidents / 10K & 480 & 502363824 & 0.0117517 & 0.2558822 & -1.697044 & 1.618357 \\
\hline Govt Initiated Incidents (GI) & 480 & 502363824 & 0.01189 & 0.1866488 & -1.849644 & 1.63037 \\
\hline Total GI Fatalities & 480 & 502363824 & -0.0019671 & 0.0891239 & -0.8093589 & 0.8093589 \\
\hline Govt Fatalities & 480 & 502363824 & 0.0009655 & 0.0307652 & -0.462789 & 0.4064789 \\
\hline Rebel Fatalities & 480 & 502363824 & -0.0027906 & 0.0690093 & -0.5395726 & 0.5395726 \\
\hline Civilian Fatalities & 480 & 502363824 & -0.000142 & 0.0126537 & -0.1195494 & 0.1195494 \\
\hline Rebel Initiated Incidents (RI) & 480 & 502363824 & -0.0001129 & 0.1165021 & -0.8959716 & 0.7241455 \\
\hline Total RI Fatalities & 480 & 502363824 & -0.0055969 & 0.0885958 & -0.6095483 & 0.8589457 \\
\hline Govt Fatalities & 480 & 502363824 & -0.0030554 & 0.0523314 & -0.6095483 & 0.609367 \\
\hline Rebel Fatalities & 480 & 502363824 & -0.0001815 & 0.0369223 & -0.5984372 & 0.7116066 \\
\hline Civilian Fatalities & 480 & 502363824 & -0.00236 & 0.0461349 & -0.2863266 & 0.3781036 \\
\hline $\begin{array}{l}\text { Value of Industrial Building } \\
\text { Permits per Capita (PHP) }\end{array}$ & 480 & 502363824 & -0.00132 & 0.1087733 & -1.284107 & 1.27067 \\
\hline $\begin{array}{l}\text { Lagged Value of Industrial } \\
\text { Building Permits per Capita }\end{array}$ & 400 & 422998661 & 0.0018524 & 0.1153617 & -1.284107 & 1.27067 \\
\hline
\end{tabular}

Note: Each observation is a province-year, over the seven years 2002 through 2008, for 80 provinces, NT $=560$ for levels and 480 for first differences less 80 for lagged variables. All population figures are extrapolated based on the censuses of 2000 and 2007. Means and standard deviations are weighted by estimated population. The variable "weight" reports the sum of weights over all NT province-years. 
Table 3A: Rebel Violence, Government Violence, and Investment - Full Sample

\begin{tabular}{|c|c|c|c|c|c|c|c|c|c|c|c|c|}
\hline & LEVELS & \multicolumn{11}{|c|}{ FIRST DIFFERENCES } \\
\hline & \multirow[b]{2}{*}{ (1) } & \multirow[b]{2}{*}{ (2) } & \multicolumn{5}{|c|}{ GOVERNMENT INITIATED INCIDENTS (GI) } & \multicolumn{5}{|c|}{ REBEL INITIATED INCIDENTS (RI) } \\
\hline & & & (3) & (4) & (5) & (6) & $(7)$ & (8) & (9) & $(10)$ & (11) & (12) \\
\hline $\begin{array}{l}\text { Left hand } \\
\text { side variable }\end{array}$ & $\begin{array}{c}\text { All } \\
\text { Incidents }\end{array}$ & $\begin{array}{c}\text { All } \\
\text { Incidents }\end{array}$ & $\begin{array}{c}\text { All GI } \\
\text { Incidents }\end{array}$ & $\begin{array}{c}\text { All GI } \\
\text { Fatalities }\end{array}$ & $\begin{array}{l}\text { GI Govt } \\
\text { Fatalities }\end{array}$ & $\begin{array}{l}\text { GI Rebel } \\
\text { Fatalities }\end{array}$ & $\begin{array}{c}\text { GI } \\
\text { Civilian } \\
\text { Fatalities }\end{array}$ & $\begin{array}{c}\text { All RI } \\
\text { Incidents }\end{array}$ & $\begin{array}{c}\text { All RI } \\
\text { Fatalities }\end{array}$ & $\begin{array}{l}\text { RI Govt } \\
\text { Fatalities }\end{array}$ & $\begin{array}{l}\text { RI Rebel } \\
\text { Fatalities }\end{array}$ & $\begin{array}{c}\text { RI } \\
\text { Civilian } \\
\text { Fatalities }\end{array}$ \\
\hline $\begin{array}{l}\text { Value of } \\
\text { industrial } \\
\text { building } \\
\text { permits }\end{array}$ & $\begin{array}{c}-1.017 * * * \\
(0.294)\end{array}$ & $\begin{array}{c}0.108^{*} \\
(0.0579)\end{array}$ & $\begin{array}{l}0.0432 \\
(0.0533)\end{array}$ & $\begin{array}{c}0.0942^{* *} \\
(0.0421)\end{array}$ & $\begin{array}{l}0.0281 * \\
(0.0156)\end{array}$ & $\begin{array}{c}0.0696^{* * *} \\
(0.0264)\end{array}$ & $\begin{array}{l}-0.00349 \\
(0.00339)\end{array}$ & $\begin{array}{c}0.0514 \\
(0.0444)\end{array}$ & $\begin{array}{c}0.0439 \\
(0.0341)\end{array}$ & $\begin{array}{c}0.0183 \\
(0.0142)\end{array}$ & $\begin{array}{c}0.0126^{*} \\
(0.00733)\end{array}$ & $\begin{array}{l}0.0130 \\
(0.0210)\end{array}$ \\
\hline Constant & $\begin{array}{c}0.317^{* * *} \\
(0.0565)\end{array}$ & $\begin{array}{c}0.0409 \\
(0.0253)\end{array}$ & $\begin{array}{c}0.0153 \\
(0.0150)\end{array}$ & $\begin{array}{c}0.0105 \\
(0.00678)\end{array}$ & $\begin{array}{c}0.00122 \\
(0.00159)\end{array}$ & $\begin{array}{c}0.00841 \\
(0.00630)\end{array}$ & $\begin{array}{c}0.000843 \\
(0.000981)\end{array}$ & $\begin{array}{l}0.0256^{*} \\
(0.0140)\end{array}$ & $\begin{array}{c}0.0308^{* *} \\
(0.0125)\end{array}$ & $\begin{array}{l}0.00991 * \\
(0.00548)\end{array}$ & $\begin{array}{c}0.00925 \\
(0.00581)\end{array}$ & $\begin{array}{c}0.0116^{*} \\
(0.00671)\end{array}$ \\
\hline Observations & 560 & 480 & 480 & 480 & 480 & 480 & 480 & 480 & 480 & 480 & 480 & 480 \\
\hline $\begin{array}{l}\text { R-squared } \\
\text { Mean LHS } \\
\text { variable }\end{array}$ & $\begin{array}{l}0.068 \\
0.409 \\
\end{array}$ & $\begin{array}{c}0.023 \\
0.0118 \\
\end{array}$ & $\begin{array}{r}0.017 \\
0.0119 \\
\end{array}$ & $\begin{array}{c}0.034 \\
-0.00197\end{array}$ & $\begin{array}{c}0.015 \\
0.000965\end{array}$ & $\begin{array}{c}0.035 \\
-0.00279\end{array}$ & $\begin{array}{c}0.010 \\
-0.000142\end{array}$ & $\begin{array}{c}0.036 \\
-0.000113\end{array}$ & $\begin{array}{c}0.040 \\
-0.00560\end{array}$ & $\begin{array}{c}0.029 \\
-0.00306 \\
\end{array}$ & $\begin{array}{c}0.020 \\
-0.000181\end{array}$ & $\begin{array}{c}0.028 \\
-0.00236\end{array}$ \\
\hline
\end{tabular}

All specifications include a complete set of year indicators. Regressions are weighted by estimated population. Robust standard errors in parentheses, clustered by province. First differenced specifications are chosen over fixed effects because of suspected nonstationarity of incidents per capita in levels (Breitung panel unit root test has $\mathrm{p}=0.925$ for rejecting a null hypothesis of a unit root in levels of per capita incidents, allowing for demeaning and trends. For changes in per capita incidents that statistic is $\mathrm{p}=0.000$, lambda $=-4.85$.) $* * * \mathrm{p}<0.01, * * \mathrm{p}<0.05, * \mathrm{p}<0.1$ 
Table 3B: Rebel Violence, Government Violence, and Investment - Zambales Province Excluded

\begin{tabular}{|c|c|c|c|c|c|c|c|c|c|c|c|c|}
\hline & LEVELS & \multicolumn{11}{|c|}{ FIRST DIFFERENCES } \\
\hline & \multirow{3}{*}{$\begin{array}{c}(1) \\
\text { All } \\
\text { Incidents }\end{array}$} & \multirow[b]{2}{*}{$(2)$} & \multicolumn{5}{|c|}{ GOVERNMENT INITIATED INCIDENTS (GI) } & \multicolumn{5}{|c|}{ REBEL INITIATED INCIDENTS (RI) } \\
\hline & & & (3) & (4) & (5) & (6) & (7) & (8) & (9) & $(10)$ & (11) & $(12)$ \\
\hline $\begin{array}{l}\text { Left hand side } \\
\text { variable }\end{array}$ & & $\begin{array}{c}\text { All } \\
\text { Incidents } \\
\end{array}$ & $\begin{array}{c}\text { All GI } \\
\text { Incidents }\end{array}$ & $\begin{array}{c}\text { All GI } \\
\text { Fatalities }\end{array}$ & $\begin{array}{l}\text { GI Govt } \\
\text { Fatalities }\end{array}$ & $\begin{array}{l}\text { GI Rebel } \\
\text { Fatalities } \\
\end{array}$ & $\begin{array}{c}\text { GI } \\
\text { Civilian } \\
\text { Fatalities } \\
\end{array}$ & $\begin{array}{c}\text { All RI } \\
\text { Incidents }\end{array}$ & $\begin{array}{c}\text { All RI } \\
\text { Fatalities } \\
\end{array}$ & $\begin{array}{l}\text { RI Govt } \\
\text { Fatalities }\end{array}$ & $\begin{array}{l}\text { RI Rebel } \\
\text { Fatalities }\end{array}$ & $\begin{array}{c}\text { RI } \\
\text { Civilian } \\
\text { Fatalities } \\
\end{array}$ \\
\hline $\begin{array}{l}\text { Value of building } \\
\text { permits }\end{array}$ & $\begin{array}{c}-1.229 * * * \\
(0.322)\end{array}$ & $\begin{array}{c}0.118 \\
(0.0897)\end{array}$ & $\begin{array}{c}-0.000866 \\
(0.0615)\end{array}$ & $\begin{array}{c}0.0407^{*} \\
(0.0238)\end{array}$ & $\begin{array}{c}0.00724 \\
(0.00738)\end{array}$ & $\begin{array}{l}0.0396^{*} \\
(0.0203)\end{array}$ & $\begin{array}{l}-0.00611 \\
(0.00502)\end{array}$ & $\begin{array}{l}0.104 * * \\
(0.0491)\end{array}$ & $\begin{array}{l}0.0793 * \\
(0.0432)\end{array}$ & $\begin{array}{l}0.0193 \\
(0.0225)\end{array}$ & $\begin{array}{c}0.0188 * \\
(0.00970)\end{array}$ & $\begin{array}{l}0.0412^{* *} \\
(0.0191)\end{array}$ \\
\hline Constant & $\begin{array}{c}0.328^{* * *} \\
(0.0574)\end{array}$ & $\begin{array}{c}0.0401 \\
(0.0255)\end{array}$ & $\begin{array}{c}0.0156 \\
(0.0151)\end{array}$ & $\begin{array}{c}0.0105 \\
(0.00685)\end{array}$ & $\begin{array}{c}0.00135 \\
(0.00161)\end{array}$ & $\begin{array}{c}0.00829 \\
(0.00635)\end{array}$ & $\begin{array}{c}0.000864 \\
(0.000991)\end{array}$ & $\begin{array}{l}0.0245^{*} \\
(0.0140)\end{array}$ & $\begin{array}{c}0.0298^{* *} \\
(0.0124)\end{array}$ & $\begin{array}{l}0.00960 * \\
(0.00549)\end{array}$ & $\begin{array}{c}0.00929 \\
(0.00585)\end{array}$ & $\begin{array}{c}0.0109 \\
(0.00666)\end{array}$ \\
\hline Observations & 553 & 474 & 474 & 474 & 474 & 474 & 474 & 474 & 474 & 474 & 474 & 474 \\
\hline R-squared & 0.082 & 0.023 & 0.018 & 0.025 & 0.008 & 0.028 & 0.011 & 0.040 & 0.041 & 0.028 & 0.021 & 0.032 \\
\hline Mean LHS variable & 0.0118 & 0.0118 & 0.0120 & -0.00193 & 0.000976 & -0.00276 & -0.000143 & -0.000161 & -0.00567 & -0.00312 & -0.000183 & -0.00237 \\
\hline
\end{tabular}

All specifications include a complete set of year indicators. Regressions are weighted by estimated population. Robust standard errors in parentheses, clustered by province. First differenced specifications are chosen over fixed effects because of suspected nonstationarity of incidents per capita in levels (Breitung panel unit root test has $\mathrm{p}=0.925$ for rejecting a null hypothesis of a unit root in levels of per capita incidents, allowing for demeaning and trends. For changes in per capita incidents that statistic is $\mathrm{p}=0.000$, lambda $=-4.85$.) $* * * \mathrm{p}<0.01,{ }^{* *} \mathrm{p}<0.05, * \mathrm{p}<0.1$ 
Table 4A: Violence and Past Investment - Full Sample

\begin{tabular}{|c|c|c|c|c|c|c|c|c|c|c|c|c|}
\hline & LEVELS & \multicolumn{11}{|c|}{ FIRST DIFFERENCES } \\
\hline & \multirow[b]{2}{*}{ (1) } & & \multicolumn{5}{|c|}{ GOVERNMENT INITIATED INCIDENTS (GI) } & \multicolumn{5}{|c|}{ REBEL INITIATED INCIDENTS (RI) } \\
\hline $\begin{array}{l}\text { Left } \\
\text { hand } \\
\text { side } \\
\text { variable }\end{array}$ & & $\begin{array}{c}\text { All } \\
\text { Incidents }\end{array}$ & $\begin{array}{c}\text { All GI } \\
\text { Incidents }\end{array}$ & $\begin{array}{c}\text { All GI } \\
\text { Fatalities }\end{array}$ & $\begin{array}{l}\text { GI Govt } \\
\text { Fatalities }\end{array}$ & $\begin{array}{l}\text { GI Rebel } \\
\text { Fatalities }\end{array}$ & $\begin{array}{c}\text { (7) } \\
\text { GI } \\
\text { Civilian } \\
\text { Fatalities }\end{array}$ & $\begin{array}{c}\text { All RI } \\
\text { Incidents }\end{array}$ & $\begin{array}{c}\text { All RI } \\
\text { Fatalities }\end{array}$ & $\begin{array}{l}\text { RI Govt } \\
\text { Fatalities }\end{array}$ & $\begin{array}{l}\text { RI Rebel } \\
\text { Fatalities }\end{array}$ & $\begin{array}{c}\text { (12) } \\
\text { RI } \\
\text { Civilian } \\
\text { Fatalities }\end{array}$ \\
\hline $\begin{array}{l}\text { Value } \\
\text { indust. } \\
\text { building } \\
\text { permits }\end{array}$ & $\begin{array}{c}-1.097 * * * \\
(0.292)\end{array}$ & $\begin{array}{c}-0.0859 * \\
(0.0492)\end{array}$ & $\begin{array}{l}-0.0699 \\
(0.0445)\end{array}$ & $\begin{array}{c}-0.0740^{* * *} \\
(0.0224)\end{array}$ & $\begin{array}{l}-0.020 * * * \\
(0.00632)\end{array}$ & $\begin{array}{c}-0.047 * * * \\
(0.0150)\end{array}$ & $\begin{array}{l}-0.00705 \\
(0.00760)\end{array}$ & $\begin{array}{l}-0.0135 \\
(0.0189)\end{array}$ & $\begin{array}{l}0.00376 \\
(0.0158)\end{array}$ & $\begin{array}{c}9.10 \mathrm{e}-05 \\
(0.0111)\end{array}$ & $\begin{array}{c}-0.000462 \\
(0.00510)\end{array}$ & $\begin{array}{l}0.00413 \\
(0.0135)\end{array}$ \\
\hline Const. & $\begin{array}{c}0.339 * * * \\
(0.0622)\end{array}$ & $\begin{array}{l}0.00443 \\
(0.0361)\end{array}$ & $\begin{array}{l}0.00870 \\
(0.0199)\end{array}$ & $\begin{array}{c}-0.0282^{* * *} \\
(0.0106)\end{array}$ & $\begin{array}{l}-0.00227 \\
(0.00193)\end{array}$ & $\begin{array}{l}-0.025^{* * *} \\
(0.00914)\end{array}$ & $\begin{array}{c}-0.000868 \\
(0.00098)\end{array}$ & $\begin{array}{l}-0.00761 \\
(0.0176)\end{array}$ & $\begin{array}{l}-0.0130 \\
(0.0123)\end{array}$ & $\begin{array}{l}-0.00932 \\
(0.00631)\end{array}$ & $\begin{array}{l}-0.00712 \\
(0.00510)\end{array}$ & $\begin{array}{c}0.00341 \\
(0.00740)\end{array}$ \\
\hline Obs. & 480 & 400 & 400 & 400 & 400 & 400 & 400 & 400 & 400 & 400 & 400 & 400 \\
\hline $\begin{array}{l}\text { R-sqr. } \\
\text { Mean } \\
\text { LHS } \\
\text { variable }\end{array}$ & 0.0118 & 0.023 & 0.0119 & -0.00197 & 0.00097 & -0.00279 & -0.000142 & -0.00011 & -0.00560 & -0.00306 & -0.000181 & -0.00236 \\
\hline
\end{tabular}

All specifications include a complete set of year indicators. Regressions are weighted by estimated population. Robust standard errors in parentheses, clustered by province. First differenced specifications are chosen over fixed effects because of suspected nonstationarity of incidents per capita in levels (Breitung panel unit root test has $\mathrm{p}=0.925$ for rejecting a null hypothesis of a unit root in levels of per capita incidents, allowing for demeaning and trends. For changes in per capita incidents that statistic is $\mathrm{p}=0.000$, lambda $=-4.85$.) ${ }^{* * *} \mathrm{p}<0.01,{ }^{* *} \mathrm{p}<0.05, * \mathrm{p}<0.1$ 
Table 4B: Violence and Past Investment - Excluding Zambales Province

\begin{tabular}{|c|c|c|c|c|c|c|c|c|c|c|c|c|}
\hline & LEVELS & \multicolumn{11}{|c|}{ FIRST DIFFERENCES } \\
\hline & \multirow{3}{*}{$(1)$} & \multirow[b]{2}{*}{$(2)$} & \multicolumn{5}{|c|}{ GOVERNMENT INITIATED INCIDENTS (GI) } & \multicolumn{5}{|c|}{ REBEL INITIATED INCIDENTS (RI) } \\
\hline & & & (3) & (4) & (5) & (6) & $(7)$ & (8) & (9) & (10) & (11) & (12) \\
\hline \multirow{3}{*}{$\begin{array}{l}\text { Left hand side } \\
\text { variable }\end{array}$} & & & & & & & GI & & & & & RI \\
\hline & All & All & All GI & All GI & GI Govt & GI Rebel & Civilian & All RI & All RI & RI Govt & RI Rebel & Civilian \\
\hline & Incidents & Incidents & Incidents & Fatalities & Fatalities & Fatalities & Fatalities & Incidents & Fatalities & Fatalities & Fatalities & Fatalities \\
\hline Lagged value of & $-1.305^{* * *}$ & -0.0646 & -0.0320 & $-0.0549 *$ & $-0.0128 * *$ & $-0.0305^{* *}$ & -0.0115 & -0.0334 & -0.00460 & 0.00919 & -0.00126 & -0.0125 \\
\hline industrial building & $(0.334)$ & $(0.0797)$ & $(0.0624)$ & $(0.0282)$ & $(0.00594)$ & $(0.0140)$ & $(0.0125)$ & $(0.0241)$ & $(0.0243)$ & $(0.0160)$ & $(0.00824)$ & $(0.0146)$ \\
\hline permits & & & & & & & & & & & & \\
\hline \multirow[t]{2}{*}{ Constant } & $0.349 * * *$ & 0.00401 & 0.00770 & $-0.0300 * * *$ & -0.00295 & $-0.0262 * * *$ & -0.000851 & -0.00691 & -0.0127 & -0.00944 & -0.00717 & 0.00392 \\
\hline & $(0.0630)$ & $(0.0364)$ & $(0.0201)$ & $(0.0106)$ & $(0.00184)$ & $(0.00922)$ & $(0.000989)$ & $(0.0177)$ & $(0.0124)$ & $(0.00638)$ & $(0.00515)$ & $(0.00743)$ \\
\hline Observations & 474 & 395 & 395 & 395 & 395 & 395 & 395 & 395 & 395 & 395 & 395 & 395 \\
\hline R-squared & 0.104 & 0.023 & 0.020 & 0.025 & 0.009 & 0.025 & 0.016 & 0.032 & 0.007 & 0.021 & 0.013 & 0.013 \\
\hline Mean LHS variable & 0.0118 & 0.0118 & 0.0120 & -0.00193 & 0.000976 & -0.00276 & -0.000143 & -0.000161 & -0.00567 & -0.00312 & -0.000183 & -0.00237 \\
\hline
\end{tabular}

All specifications include a complete set of year indicators. Regressions are weighted by estimated population. Robust standard errors in parentheses, clustered by province. First differenced specifications are chosen over fixed effects because of suspected nonstationarity of incidents per capita in levels (Breitung panel unit root test has $\mathrm{p}=0.925$ for rejecting a null hypothesis of a unit root in levels of per capita incidents, allowing for demeaning and trends. For changes in per capita incidents that statistic is $\mathrm{p}=0.000$, lambda $=-4.85.) * * * \mathrm{p}<0.01, * * \mathrm{p}<0.05, * \mathrm{p}<0.1$ 


\section{Appendix: Proofs of Propositions}

Proposition \#1: The community will share information with government if and only if the value of services provided and the costs of violence exceed norms of noncooperation.

Proof of Proposition \#1:

The community chooses $i$ on the closed interval $[0,1]$ to maximize expected utility,

$\left.\max _{0 \leq i \leq 1} \mathrm{EU}_{\mathrm{C}}(y, i, g, n, v, m)\right|_{\mathrm{n}}=\mathrm{u}\left[\left(1-\theta_{\mathrm{G}}\right) y+g-n\right] p(m, i)+\mathrm{u}\left[\left(1-\theta_{\mathrm{R}}\right) y-v\right](1-p(m, i))$.

Note that since the probability of control is proportional to information shared, public good

provision and information are complements, as are counterinsurgency effort and information. Since C chooses $i, \frac{\partial p}{\partial i}=\mathrm{h}(m)$, so the first order condition for $\mathrm{C}$ is

$0 \geq \frac{\partial E U c}{\partial i}=\mathrm{u}[c+g-n] \mathrm{h}(m)-\mathrm{u}[c-v] \mathrm{h}(m)$,

which implies that either $m=0$ or that the best response function of the community is

$$
\text { (4) } \quad i^{*}=\left\{\begin{array}{l}
0 \text { if } \mathrm{u}[c+g-n] \leq \mathrm{u}[c-v] \leftrightarrow n \geq g+v \\
1 \text { if } \mathrm{u}[c+g-n]>\mathrm{u}[c-v] \leftrightarrow n<g+v
\end{array}\right.
$$

where the equivalent conditions to the right follow from $\mathrm{u}($.$) being strictly monotonic. Proposition$ \#2 rules out the case where $m=0$.

Note: In proofs below it will be useful to define $p^{*} \equiv \phi\left(i^{*}, m\right)$, the probability of government control, anticipating optimal information sharing by the community. If $m>0$ then $\mathrm{E}\left(\imath^{*}\right)=\mathrm{P}\left(i^{*}=1\right)=\mathrm{P}(n<g+v)=\mathrm{F}(g+v)=\left(g+v-n_{L}\right) f$, where $f=\frac{1}{n_{U}-n_{L}}$, the density of the uniform distribution, so that

$$
\begin{gathered}
p^{*}=\left(g+v-n_{L}\right) f \mathrm{~h}(m) \text { if } m>0, \\
\text { or } p^{*}=0 \text { if } m=0 .
\end{gathered}
$$

Proposition \#2: A unique Nash equilibrium in pure strategies exists for this game.

Proof:

First we show that all choice variables in steps \#2 and \#3 have best response functions, then we invoke concavity and convexity of objective functions to show existence and uniqueness.

For a proof that enforcement, $m$, is strictly positive see BSF. Note that this resolves the ambiguity in step \#3 so that $i^{*}$ is determined by equation (4) and $p^{*}$ by equation (5).

The proof of uniqueness requires continuing backwards through the sequence of play to step \#2 (in which government, rebels and firms make simultaneous choices). The government anticipates 
optimal behavior of $C$ and minimizes expected costs by optimally choosing $m$ and $g$, trading off reductions in expected damage against the marginal costs of counterinsurgency and service provision. G solves

$$
\min _{g \geq 0, m \geq 0} \mathrm{EC}_{\mathrm{G}}\left(v, m, g, p^{*}, I\right)=\mathrm{A}(v)\left[1-p^{*}\right]+\mathrm{D}(m)+\mathrm{H}(g)-\theta_{\mathrm{G}} I p^{*},
$$

where $p^{*}$ is defined in (5) in the note above. The first order condition for $m$ is $0 \leq \frac{\partial E C_{G}}{\partial m}=-[\mathrm{A}(v)+$ $\left.\theta_{\mathrm{G}} I\right]\left(g+v-n_{L}\right) f \mathrm{~h}^{\prime}(m)+\mathrm{D}^{\prime}(m)$, which for an interior solution equates the marginal cost of counterinsurgency effort to the marginal benefit in reduced expected violence costs and increased expected tax revenue. Solving for enforcement, $\frac{\partial^{2} E C_{G}}{\partial m^{2}}=-\left[\mathrm{A}(v)+\theta_{\mathrm{G}} I\right]\left(g+v-n_{L}\right) f \mathrm{~h}^{\prime \prime}(m)+\mathrm{D}^{\prime \prime}(m)>$ 0 . (Recalling that $g+v>n_{L}$ and $\mathrm{h}^{\prime \prime}(m)<0$ by assumption.) Thus $m$ has a unique interior solution $m^{*}>$ 0 , given $v, g$ and $I$, defining a best response function for enforcement $m^{*}(v, g, I)$.

The government chooses a level of services, $g^{*}$, that solves the first order condition $0 \leq \frac{\partial E C_{G}}{\partial g}=-[\mathrm{A}(v$ )$+\theta_{\mathrm{G}} I f \mathrm{~h}(m)+\mathrm{H}^{\prime}(g)$, which for an interior solution equates the marginal cost of services to the marginal benefit in reduced expected costs of violence and increased expected tax revenue. $\frac{\partial^{2} E C_{G}}{\partial g^{2}}=$ $\mathrm{H}^{\prime \prime}(g)>0$, which ensures a unique interior solution at some $g^{*}>0$, defining a best response function for government services, $g^{*}(v, m, I)$.

Rebels choose a level of violence to maximize expected violence costs imposed on government, anticipating optimal behavior of C. $\max _{v \geq 0} \mathrm{EU}_{\mathrm{R}}\left(y, v, g, m, p^{*}\right)=\left[\mathrm{A}(v)+\theta_{\mathrm{R}}(v) I\right]\left(1-p^{*}\right)-\mathrm{B}(v, I)$. The first order condition $0 \geq \frac{\partial E U_{R}}{\partial v}=\left[\mathrm{A}^{\prime}(v)+\theta_{\mathrm{R}}{ }^{\prime}(v) I\right]\left(1-p^{*}\right)-\left[\mathrm{A}(v)+\theta_{\mathrm{R}}(v) I\right] f \mathrm{~h}(m)-\frac{\partial B(v, I)}{\partial v}$, indicates how rebels weigh the marginal benefit of increased violence against the increased probability of government control and increased marginal costs. The second order condition, $\frac{\partial^{2} E U_{R}}{\partial v^{2}}=\left[\mathrm{A}^{\prime \prime}(v)+\theta_{\mathrm{R}}{ }^{\prime \prime}(v) I\right]\left(1-p^{*}\right)-2\left[\mathrm{~A}^{\prime}(v)+\theta_{\mathrm{R}}{ }^{\prime}(v) I\right] f \mathrm{~h}(m)-\frac{\partial^{2} B(v, I)}{\partial v^{2}}<0$, so that $v^{*}$ is a unique maximum (due to the concavity of $\mathrm{A}($.$) and \theta_{\mathrm{R}}$, and the convexity of $\mathrm{B}($.$) ), given g$ and $v$. Thus the first order condition defines R's best response function $v^{*}(g, m, I)$. Since $\mathrm{A}(0)=0$ and $\mathrm{A}^{\prime}>0, v^{*}$ must be positive.

Firms solve $\max _{0 \leq I}, \mathrm{E} \Pi(v, m, g, a, I)=\chi(I)-I-\left[\theta_{G} p^{*}+\theta_{R}\left(1-p^{*}\right)\right] I$ which yields a first order condition

$$
0 \leq \frac{\partial}{\partial I} \mathrm{E} \Pi(v, m, g, a, I)=x^{\prime}(I)-1-\left[\theta_{G} p^{*}+\theta_{R}\left(1-p^{*}\right)\right] .
$$


The concavity of $x($.$) implies a negative second derivative, which together with a condition on the$ profitability of the first unit implies a unique interior maximum at some positive level of investment I. Thus the first order condition holds with equality, defining a best response function $I^{*}(m, v, g)$.

Collecting first order conditions for the four players, equilibrium will be characterized by five equations in five unknowns.

We have a closed form solution for optimal information sharing by $\mathrm{C}$ in stage \#3

$$
i^{*}=\left\{\begin{array}{l}
0 \text { if } n \geq g+v \\
1 \text { if } n<g+v
\end{array} .\right.
$$

In stage \#2, four equations in four unknowns determine best response functions $m^{*}(v, g, I)$ and $g^{*}(v$, $m, I)$ for $\mathrm{G}, v^{*}(g, m, I)$ for $\mathrm{R}$ in and $I^{*}(m, v, g)$ for $\mathrm{F}$, in stage \#2:

$$
\begin{aligned}
& 0=\frac{\partial E C_{G}}{\partial m}=-\left[\mathrm{A}(v)+\theta_{\mathrm{G}} I\right]\left(g+v-n_{L}\right) f h^{\prime}\left(m^{*}\right)+\mathrm{D}^{\prime}\left(m^{*}\right), \\
& 0=\frac{\partial E C_{G}}{\partial g}=-\left[\mathrm{A}(v)+\theta_{\mathrm{G}} I\right] f h(m)+\mathrm{H}^{\prime}\left(g^{*}\right), \\
& \left.0=\frac{\partial E U_{R}}{\partial v}=\left[\mathrm{A}^{\prime}\left(v^{*}\right)+\theta_{\mathrm{R}}{ }^{\prime}\left(v^{*}\right) I\right]\left(1-p^{*}\right)-\left[\mathrm{A}\left(v^{*}\right)+\theta_{\mathrm{R}}\left(v^{*}\right) I\right] f \mathrm{~h}(m)\right)-\frac{\partial B(v, I)}{\partial v}, \text { and } \\
& 0=\frac{\partial}{\partial I} \mathrm{E} \Pi(v, m, g, a, I)=x^{\prime}\left(I^{*}\right)-1-\left[\theta_{G} p^{*}+\theta_{R}(v)\left(1-p^{*}\right)\right] .
\end{aligned}
$$

Though in general we cannot solve closed form solutions for $m^{*}, g^{*}, v^{*}$ and $I^{*}$, the concavity of $\mathrm{EU}_{\mathrm{R}}$ and $\mathrm{E} \Pi$ and the convexity of $\mathrm{EC}_{\mathrm{G}}$ ensure existence of a unique Nash equilibrium for the game. ${ }^{18}$

Proposition \#3: In regions where norms favor rebels, communities have a lower probability of sharing information with government, rebels choose to use more violence, government chooses to provide less enforcement, and government provision of services is the same, all ceteris paribus.

Proof:

A shift in norms towards rebels is a change in the endpoints of the uniform distribution $\mathrm{F}(n)$, in which $\Delta n_{L}=\Delta n_{U}$. Note that this shift leaves $f=\frac{1}{n_{U}-n_{L}}$, the density of the uniform distribution, unchanged. The probability that communities share information is $\mathrm{E}\left(i^{*}\right)=\mathrm{P}\left(i^{*}=1\right)=\mathrm{P}(n<g+v)=$ $\mathrm{F}(g+v)=\left(g+v-n_{L}\right) f$, so the effect on information sharing of a shift in norms toward rebels is given by $\mathrm{dE}\left(\imath^{*}\right) /\left.\mathrm{d} n_{L}\right|_{m, g, v}=-f$. The effect on violence of a shift in norms is $\mathrm{d} \nu^{*} /\left.\mathrm{d} n_{L}\right|_{m, g, I}=-\left.\frac{\partial^{2} E U_{R}}{\partial v \partial n_{L}}\right|_{m, g, I} /$ $\left.\frac{\partial^{2} E U_{R}}{\partial v^{2}}\right|_{m, g, I}$, by the implicit function theorem. The denominator is negative (see proposition \#2) and

${ }^{18}$ See Mas-Collel, Whinston, and Green, proposition 8.D.3. 
the numerator is - $\mathrm{d}\left[\mathrm{A}^{\prime}(v)+\theta_{\mathrm{R}}{ }^{\prime}(v) I\right]\left(1-p^{*}\right) /\left.\mathrm{d} n_{L}\right|_{m, g, I}=-\left[\mathrm{A}^{\prime}(v)+\theta_{\mathrm{R}}{ }^{\prime}(v) I\right] f \mathrm{~h}(m)<0$, so $\mathrm{d} v^{*} /\left.\mathrm{d} n_{L}\right|_{m, g, I}$ $>0$. For government, the effect on enforcement of a shift in norms is $\mathrm{d} m^{*} /\left.\mathrm{d} n_{L}\right|_{m, g, I}=-\left.\frac{\partial^{2} E C_{G}}{\partial m \partial n_{L}}\right|_{v, g, I} /$ $\left.\frac{\partial^{2} E C_{G}}{\partial m^{2}}\right|_{v, g, I}$. The denominator is positive and the numerator is $\left[\mathrm{A}(v)+\theta_{\mathrm{G}} I\right] f h^{\prime}\left(m^{*}\right)>0$, so $\mathrm{d} m^{*} /\left.\mathrm{d} n_{L}\right|_{m, g}$ $<0$. Finally, the effect on government service provision of a shift in norms is $\mathrm{d} g^{*} /\left.\mathrm{d} n_{L}\right|_{m, v, I}=-$

$\left.\frac{\partial^{2} E C_{G}}{\partial g \partial n_{L}}\right|_{m, v, I} /\left.\frac{\partial^{2} E C_{G}}{\partial g^{2}}\right|_{m, v, I}$. The denominator is positive and the numerator is zero. So $\mathrm{d} g^{*} /\left.\mathrm{d} n_{L}\right|_{m, v, I}=0$.

Proposition \#4: Investment is higher (lower) where norms favor government if and only if the government tax rate is less than (exceeds) the rebel extortion rate, ceteris paribus.

Proof:

$\mathrm{d} I^{*} /\left.\mathrm{d} n_{L}\right|_{m, g, v}=-\left.\frac{\partial^{2} E \pi}{\partial I \partial n_{L}}\right|_{m, g, v} /\left.\frac{\partial^{2} E \pi}{\partial I^{2}}\right|_{m, g, v}$. The denominator is negative because of the concavity of

$x($.$) . The numerator is the cross partial derivative \left.\frac{\partial^{2} E \pi}{\partial I \partial n_{L}}\right|_{m, g, v}=\left(\theta_{R}-\theta_{G}\right) \mathrm{d} p^{*} / \mathrm{d} n_{L}$

$=-\left(\theta_{R}-\theta_{G}\right) f \mathrm{~h}(m)$. So sgn $\left(\mathrm{d} I^{*} /\left.\mathrm{d} n_{L}\right|_{m, g, v}\right)=\operatorname{sgn}\left(\theta_{G}-\theta_{R}\right)$.

Proposition \#5: Government enforcement and service provision both increase in rebel violence, ceteris paribus.

Proof:

The government chooses a level of services, $g^{*}$, that solves the first order condition $0=\frac{\partial E C_{G}}{\partial g}=-[\mathrm{A}(\nu$ )$+\theta_{\mathrm{G}} I f \mathrm{~h}(m)+\mathrm{H}^{\prime}(g)$, which equates the marginal cost of services to the marginal benefit in reduced expected costs of violence and increased expected tax revenue. $\frac{\partial^{2} E C_{G}}{\partial g^{2}}=\mathrm{H}^{\prime \prime}(g)>0$. $\left.\frac{\partial^{2} E C_{G}}{\partial g \partial v}\right|_{m}=-\mathrm{A}^{\prime}(v) f \mathrm{~h}(m)<0$, so that $\left.\frac{\partial g^{*}}{\partial v}\right|_{I, m}>0$ by the implicit function theorem. Similarly, $\left.\frac{\partial^{2} E C_{G}}{\partial m \partial v}\right|_{v}=-\mathrm{A}^{\prime}(v)\left(g+v-n_{L}\right) f \mathrm{~h}^{\prime}(m)-\left[\mathrm{A}(v)+\theta_{\mathrm{G}} I\right] \mathrm{h}^{\prime}(m)<0$, so that $\left.\frac{\partial m^{*}}{\partial v}\right|_{I, g}>0$, again by the implicit function theorem. Moreover, $m$ and $g$ are strategic complements since $\left.\frac{\partial^{2} E C_{G}}{\partial g \partial m}\right|_{v, I}=-[\mathrm{A}(v)+$ $\theta_{\mathrm{G}} I f \mathrm{~h}^{\prime}(m)<0$, so that, a little more generally (i.e., less conditionally), $\left.\frac{\partial g^{*}}{\partial v}\right|_{I}>0$ and $\left.\frac{\partial m^{*}}{\partial v}\right|_{I}>0$.

Proposition \#6: Rebel violence will decline in both government enforcement, $m$, and in government service provision, $g$, ceteris paribus.

Proof: 
The first order condition $0=\frac{\partial E U_{R}}{\partial v}=\left[\mathrm{A}^{\prime}(v)+\theta_{\mathrm{R}}{ }^{\prime}(v) I\right]\left(1-p^{*}\right)-\left[\mathrm{A}(v)+\theta_{\mathrm{R}}(v) I\right] f \mathrm{~h}(m)-\frac{\partial B(v, I)}{\partial v}$, indicates how rebels weigh the marginal benefit of increased violence against the increased probability of government control and increased marginal costs. The second order condition, $\frac{\partial^{2} E U_{R}}{\partial v^{2}}=\left[\mathrm{A}^{\prime \prime}(v)+\theta_{\mathrm{R}}{ }^{\prime}(v) I\right]\left(1-p^{*}\right)-2\left[\mathrm{~A}^{\prime}(v)+\theta_{\mathrm{R}}{ }^{\prime}(v) I\right] f \mathrm{~h}(m)-\frac{\partial^{2} B(v, I)}{\partial v^{2}}<0$, (due to the concavity of $\mathrm{A}($.$) and \theta_{\mathrm{R}}$, and the convexity of $\left.\mathrm{B}().\right)$, given $g$ and $v$. To sign how rebels' optimal choice of violence responds to counterinsurgency effort, $m$, we calculate $\left.\frac{\partial^{2} E U_{R}}{\partial v \partial m}\right|_{g}=-\left[\mathrm{A}^{\prime}(v)+\theta_{\mathrm{R}}{ }^{\prime}(v) I\right]\left(g+v-n_{L}\right) f \mathrm{~h}^{\prime}(m)$ - $\left[\mathrm{A}(v)+\theta_{\mathrm{R}}(v) I\right] f \mathrm{~h}^{\prime}(m)<0$, so that $\left.\frac{\partial v^{*}}{\partial m}\right|_{g, I}<0$ by the implicit function theorem.

Rebel violence will also decline in government provision of services, since $\left.\frac{\partial^{2} E U_{R}}{\partial v \partial g}\right|_{m}=-\left[\mathrm{A}^{\prime}(v)+\right.$ $\left.\theta_{\mathrm{R}}{ }^{\prime}(v) I\right] f \mathrm{~h}(m)<0$, which implies that $\left.\frac{\partial v^{*}}{\partial g}\right|_{m, I}<0$ by the implicit function theorem. Since $\mathrm{g}$ and $\mathrm{m}$ are strategic complements (proof of Proposition \#5), we can make the slightly less conditional statements $\left.\frac{\partial v^{*}}{\partial m}\right|_{I}<0$ and $\left.\frac{\partial v^{*}}{\partial g}\right|_{I}<0$.

Proposition \#7: Government enforcement and service provision both increase in investment, ceteris paribus.

Proof:

The government chooses a level of services, $g^{*}$, that solves the first order condition $0=\frac{\partial E C_{G}}{\partial g}=-[\mathrm{A}(v$ )$+\theta_{\mathrm{G}} l f \mathrm{~h}(m)+\mathrm{H}^{\prime}(g)$, which equates the marginal cost of services to the marginal benefit in reduced expected costs of violence and increased expected tax revenue. $\left.\frac{\partial^{2} E C_{G}}{\partial g \partial I}\right|_{m, v}=-\theta_{\mathrm{G}} f \mathrm{~h}(m)<$ 0 , and $\left.\frac{\partial^{2} E C_{G}}{\partial g^{2}}\right|_{m, v}=\mathrm{H}^{\prime \prime}(g)>0$, so that $\left.\frac{\partial g^{*}}{\partial I}\right|_{m, v}>0$ by the implicit function theorem. Similarly, $\left.\frac{\partial^{2} E C_{G}}{\partial m \partial I}\right|_{v}=-\theta_{\mathrm{G}}\left(g+v-n_{L}\right) f \mathrm{~h}^{\prime}(m)<0$, so that $\left.\frac{\partial m^{*}}{\partial I}\right|_{g, v}>0$, again by the implicit function theorem. Moreover, $m$ and $g$ are strategic complements since $\left.\frac{\partial^{2} E C_{G}}{\partial g \partial m}\right|_{v}=-\left[\mathrm{A}(v)+\theta_{\mathrm{G}} I\right] f \mathrm{~h}^{\prime}(m)<0$, which implies conditionality on $m$ and $g$ can be removed (respectively), yielding the stronger results: $\left.\frac{\partial g^{*}}{\partial I}\right|_{v}>0$ and $\left.\frac{\partial m^{*}}{\partial I}\right|_{v}>0$.

Proposition \#8: Investment increases (decreases) with both enforcement and service provision, if and only if the government tax rate is less than (exceeds) the rebel extortion rate, holding violence constant. 


\section{Proof:}

The firm's first order condition $0=\frac{\partial}{\partial I} \mathrm{E} \Pi(v, m, g, a, I)=x^{\prime}\left(I^{*}\right)-1-\left[\theta_{G} p^{*}+\theta_{R}\left(1-p^{*}\right)\right]$, and the second order condition is negative, both from the proof of Proposition \#4 above. The cross partial derivative $\left.\frac{\partial^{2} E \Pi}{\partial I \partial g}\right|_{m, v}=\left(\theta_{\mathrm{R}}-\theta_{\mathrm{G}}\right) f \mathrm{~h}(m)$ has the same sign as $\theta_{\mathrm{R}}-\theta_{\mathrm{G}}$. By the implicit function theorem, the slope of the best response function of investment to government services has the same sign as this cross partial derivative, so that $\operatorname{sign}\left(\left.\frac{\partial I^{*}}{\partial g}\right|_{m, v}\right)=\operatorname{sign}\left(\theta_{\mathrm{R}}-\theta_{\mathrm{G}}\right)$. Similarly, the cross partial derivative $\left.\frac{\partial^{2} E \Pi}{\partial I \partial m}\right|_{g, v}=\left(\theta_{\mathrm{R}}-\theta_{\mathrm{G}}\right)\left(g+v-n_{L}\right) f \mathrm{~h}^{\prime}(m)$ shares the $\operatorname{sign}$ of $\theta_{\mathrm{R}}-\theta_{\mathrm{G}}$, so that $\operatorname{sign}\left(\left.\frac{\partial I}{\partial m}\right|_{g, v}\right)$ $=\operatorname{sign}\left(\theta_{\mathrm{R}}-\theta_{\mathrm{G}}\right)$. Furthermore, since $\mathrm{m}$ and $\mathrm{g}$ are strategic complements (see proof of Proposition \#5), they will move in the same direction, so that we can make the stronger statement $\operatorname{sign}\left(\left.\frac{\partial I^{*}}{\partial g}\right|_{v}\right)$ $=\operatorname{sign}\left(\left.\frac{\partial I}{\partial m}^{*}\right|_{v}\right)=\operatorname{sign}\left(\theta_{\mathrm{R}}-\theta_{\mathrm{G}}\right)$

Proposition \#9: Investment declines (increases) in violence if and only if the rate effect, $\theta_{\mathrm{R}}{ }^{\prime}(v)\left(1-p^{*}\right)$, exceeds (is less than) the incidence effect, $\left(\theta_{R^{-}} \theta_{G}\right) f h(m)$, holding enforcement and service provision constant.

Proof:

To solve $\left.\frac{\partial I^{*}}{\partial v}\right|_{m, g}$ we require the cross partial $\left.\frac{\partial^{2} E \pi}{\partial I \partial v}\right|_{m, g}=\left(\theta_{R^{-}} \theta_{G}\right) f h(m)-\theta_{\mathrm{R}}{ }^{\prime}(v)\left(1-p^{*}\right)$. The second derivative of expected profits in investment is negative (see proof of proposition \#5) so by the implicit function theorem the slope $\left.\frac{\partial I^{*}}{\partial v}\right|_{m, g}$ will have the same sign as this cross-partial derivative. $\operatorname{sign}\left(\left.\frac{\partial I^{*}}{\partial v}\right|_{m, g}\right)=\operatorname{sign}\left[\left(\theta_{R^{-}} \theta_{G}\right) f h(m)-\theta_{\mathrm{R}}{ }^{\prime}(v)\left(1-p^{*}\right)\right]$.

Proposition \#10: Violence increases (declines) in investment if and only if the rate effect, $\theta_{\mathrm{R}}{ }^{\prime}\left(\nu^{*}\right)\left(1-p^{*}\right)$, exceeds (is less than) the sum of the incidence effect, $\theta_{\mathrm{R}}\left(v^{*}\right) f \mathrm{~h}(m)$, and the opportunity cost and gratitude effects $\frac{\partial^{2} B}{\partial v \partial I}$, holding enforcement and service provision constant.

\section{Proof:}

The slope of $\left.\frac{\partial v^{*}}{\partial I}\right|_{m, g}$ has the same sign as the cross partial $\left.\frac{\partial^{2} E U_{R}}{\partial v \partial I}\right|_{m, g}$ since $\mathrm{EU}_{\mathrm{R}}$ is concave in violence. Rebels set violence according to the first order condition $0=\frac{\partial E U_{R}}{\partial v}=\left[\mathrm{A}^{\prime}(v)+\theta_{\mathrm{R}}{ }^{\prime}(v) I\right](1-$ $\left.p^{*}\right)-\left[\mathrm{A}(v)+\theta_{\mathrm{R}}(v) I\right] f \mathrm{~h}(m)-\frac{\partial B(v, I)}{\partial v}$. The cross partial derivative $\left.\frac{\partial^{2} E U_{R}}{\partial v \partial I}\right|_{m, g}=\theta_{\mathrm{R}}{ }^{\prime}\left(v^{*}\right)\left(1-p^{*}\right)-$ 
$\theta_{\mathrm{R}}\left(v^{*}\right) f \mathrm{~h}(m)-\frac{\partial^{2} B}{\partial v \partial I}$, which reflects how the marginal utility of violence for rebels is influenced by increased investment. The first term captures the rate effect, which is positive, the second captures the incidence effect, which is negative, and the third reflects the increased marginal cost of violence for rebels when investment is high, which is positive (by assumption). Thus $\operatorname{sgn}\left(\left.\frac{\partial v^{*}}{\partial I}\right|_{m, g}\right)=\operatorname{sgn}$ $\left[\theta_{\mathrm{R}}^{\prime}\left(v^{*}\right)\left(1-p^{*}\right)-\theta_{\mathrm{R}}\left(v^{*}\right) f \mathrm{~h}(m)-\frac{\partial^{2} B}{\partial v \partial I}\right]$.

Proposition \#11: If violence is increasing in investment, then investment must be decreasing in violence, holding service provision and enforcement constant.

Proof:

$\left.\frac{\partial v^{*}}{\partial I}\right|_{m, g}>0$ implies $\theta_{\mathrm{R}}{ }^{\prime}\left(\nu^{*}\right)\left(1-p^{*}\right)>\theta_{\mathrm{R}} f \mathrm{~h}(m)+\frac{\partial B(v, I)}{\partial v} \quad$ (by proposition \#10). $\frac{\partial B(v, I)}{\partial v}>0$ and $\theta_{\mathrm{G}} f$ $\mathrm{h}(m)>0$ so subtracting both from both sides implies that $\theta_{\mathrm{R}}{ }^{\prime}\left(v^{*}\right)\left(1-p^{*}\right)-\frac{\partial B(v, I)}{\partial v}>\left(\theta_{\mathrm{R}}-\theta_{\mathrm{G}}\right) f \mathrm{~h}(m)$, and that $\theta_{\mathrm{R}}{ }^{\prime}\left(v^{*}\right)\left(1-p^{*}\right)>\left(\theta_{\mathrm{R}}-\theta_{\mathrm{G}}\right) f \mathrm{~h}(m)$, so that $\left.\frac{\partial I^{*}}{\partial v}\right|_{m, g}<0$ (proposition \#9). 
